\title{
Trends in ship wind speeds adjusted for observation method and height
}

\author{
Bridget R. Thomas, ${ }^{\mathrm{a} *}$ Elizabeth C. Kent, ${ }^{\mathrm{b}}$ Val R. Swail ${ }^{\mathrm{c}}$ and David I. Berry ${ }^{\mathrm{b}}$ \\ a Environment Canada, Climate Research Division, Dartmouth, NS, Canada \\ b National Oceanography Centre, Southampton, UK \\ c Environment Canada, Climate Research Division, Toronto, ON, Canada
}

\begin{abstract}
Globally averaged wind speeds from archived ship reports show an increasing trend since the 1940s, which previous studies attributed to the gradual shift from visually estimated to anemometer-measured winds, and an increase in mean anemometer height. To test this hypothesis, adjustments to account for these changes were applied to individual ship wind observations in the International Comprehensive Ocean-Atmosphere Data Set (ICOADS). Annual means calculated from adjusted reports were compared to reanalysis near-surface winds in consistently well-sampled regions for the period 1958-2002.

The adjustments to individual ship wind reports for known biases improve the homogeneity over the entire period and remove trends, prior to the early 1980s. However, for the 21-year period 1982-2002, trends remain in the annual mean spatially averaged adjusted winds, of $0.4 \mathrm{~ms}^{-1}$ decade $^{-1}\left(6 \%\right.$ decade $\left.^{-1}\right)$ for estimated speeds, and of $0.2 \mathrm{~ms}^{-1} \mathrm{decade}^{-1}$ $\left(3 \%\right.$ decade $\left.^{-1}\right)$ for measured speeds. In contrast, co-located reanalysis near-surface wind speeds show little change, $1 \%$ decade $^{-1}$ or less. Anemometers were installed on increasing numbers of ships during the period of study, even as many of these ships continued to report estimated winds. Part of the trend in estimated wind speeds is probably spurious, most likely a result of observers being increasingly influenced by readings from anemometers located well above 10-m. This influence is indicated by the gradual reduction in the tendency to underestimate nighttime marine winds. Results confirm earlier findings that reanalysis near-surface winds were biased low. The paper summarizes methods that could be employed to account for remaining inhomogeneities and thereby improve the quality of the marine wind climate record. Copyright (c) 2007 Crown in the right of Canada. Published by John Wiley \& Sons, Ltd
\end{abstract}

KEY WORDS ICOADS; wind speed; Beaufort scale; anemometer height; climate data; inhomogeneity; trend; ship observation

Received 15 November 2006; Revised 26 April 2007; Accepted 28 April 2007

\section{Introduction}

The near-surface marine wind speed is a key parameter in air-sea interaction, and therefore a homogeneous marine wind record is vital for studies of inter-annual variability and change in the atmosphere and ocean. Monthly mean historical marine wind fields can be calculated from archived voluntary observing ship (VOS) observations contained in data sets such as the International Comprehensive Ocean-Atmosphere Data set (ICOADS) (Woodruff et al., 1987, 1998; Worley et al., 2005) or earlier data set such as Tape Data Family-11 (TDF-11, NCDC, 1968) and the UK Met Office Marine Data Bank (Woodruff et al., 2003). These indicate an apparent upward trend in average wind strength since the 1940s (Bunker, 1980; Ramage, 1987; Whysall et al., 1987; Cardone et al., 1990; Diaz et al., 1995).

Prior to the 1940 s, winds appear to have been decreasing for several decades. The transition from decreasing to increasing ship winds coincided with the establishment,

* Correspondence to: Bridget R. Thomas, Environment Canada, 16th Floor, 45 Alderney Dr., Dartmouth, NS, B2Y 2N6, Canada.

E-mail: bridget.thomas@ec.gc.ca in 1946, of an international standard scale for visually estimating the wind speed. This Beaufort Equivalent Scale, known as WMO1100, relates wind speed to the characteristics of the sea state, and is still used today (WMO, 1970). Use of wind speeds from VOS for climate trend analysis before 1946 is problematic, as wind reports evolved from those derived from the amount of sail a ship could carry to those derived from observations of the sea state (Peterson and Hasse, 1987; Ramage, 1987; Cardone et al., 1990).

The reality of the increasing trends after 1946 was also questioned, as an increasing proportion of ships began to report anemometer-measured wind speeds. WMO1100estimated winds are thought to contain systematic errors that vary non-linearly with wind speed, due to the statistical method and limited data used to derive the scale (Isemer and Hasse, 1991), causing an underestimation of climatological monthly means. Various authors developed alternative Beaufort equivalent scales, although none was adopted operationally (Cardone, 1969; WMO, 1970; Kaufeld, 1981; Isemer, 1992; da Silva et al., 1995; Lindau, 1995a). The WMO1100 scale corresponds to wind speed at 10-m, while ship anemometers tended to 
be located above the 10-m reference height. Peterson and Hasse (1987); Ramage (1987), and Cardone et al. (1990) concluded that the increasing trend in archived ship wind speeds since the 1940s was due to the increasing proportion of measured ship wind reports.

This conclusion was supported by several studies that used other indicators of near-surface atmospheric circulation, including sea-level pressure (SLP) gradients and changes in sea level, to show that the increasing trend was spurious (Ramage, 1987; Wright, 1988; Posmentier et al., 1989; Ward and Hoskins, 1996). Ward and Hoskins (1996) showed that globally averaged ship winds indicated an upward trend in circulation strength for the period 1949-1988, with no associated trend in globally averaged pressure-gradient-derived winds. Wind speed trends from the relatively homogeneous ocean weather station (OWS) data mostly showed little trend, even as nearby VOS winds increased (Isemer, 1995). However, Ward and Hoskins (1996) showed regional patterns in trends in corrected wind speed.

Thomas et al. (2005) showed the importance of height adjustment for measured winds. They compared colocated measured ship and carefully quality-controlled buoy wind speeds, from the period 1980-1995, and found the ship winds about $25 \%$ stronger. This bias reduced to $6 \%$ following height adjustment, although differences varied by ship type and other factors. Kent et al. (1998) compared height-adjusted ship and European remote sensing (ERS) scatterometer winds and found that the ships reported slightly stronger winds compared to the scatterometer.

Other factors could introduce biases in a ship wind data set. These include differences in flow distortion due to ship geometry and anemometer location (Yelland et al., 2002; Moat et al., 2005, 2006a,b), changes in composition (by ship type) of the VOS fleet, and differences in wind sampling period and averaging method (Dobson, 1981; Lindau, 1995b; Gulev, 1999; Thomas et al., 2005).

Cardone et al. (1990) attempted to adjust individual estimated and measured wind reports from the period 1946-1984, but were hindered by limited information about the observation method and the anemometer heights of individual ships. They identified anemometer heights for only about $8 \%$ of measured reports. Estimated winds, equivalent to $10-\mathrm{m}$ measured winds by definition, tended to be lighter than measured VOS winds, which were from anemometers with average heights of $20 \mathrm{~m}$. Estimated winds were adjusted using a revised Beaufort equivalent scale referenced to $20 \mathrm{~m}$ (Cardone, 1969). This reduced the positive trend to near zero in the analysed areas in the N. Pacific and Indian Oceans, while a positive trend remained in the South China Sea. Other climate applications using ship data (e.g. Bourassa et al., 2005; Uppala et al., 2005) also assume a fixed anemometer height of 20 or $25 \mathrm{~m}$. However, this would allow a spurious increasing trend in height-adjusted winds to remain, as average anemometer heights have continued to increase, to over $30 \mathrm{~m}$ by 2002 (Kent et al., 2007).
The goal of this study is to test the hypothesis that the widespread increases in VOS wind speeds since the 1940s are explained by a shift over time from nearly all winds estimated visually to predominantly winds measured by anemometer. Information is now more readily available on observing method and instrumentation, including, since 1970, anemometer height. This allows us to adjust individual ship wind reports to account for inhomogeneities. We adjust measured winds from anemometer height to 10-m, and adjust estimated winds using a revised Beaufort equivalent scale (Lindau, 1995a). We assess multi-decadal trends in scalar-mean wind speeds before and after adjustments.

In this paper, wind speeds were averaged over regions that were consistently well sampled (and well represented by metadata). This restricted the analysis areas mainly to the Northern Hemisphere (NH). The study of trends in spatially averaged data for non-global regions is problematic. For example, studies of extratropical cyclone frequency and intensity and storm tracks, and NH circulation indices (e.g. Serreze et al., 1997; The WASA Group, 1998; Thompson and Wallace, 2000; Graham and Diaz, 2001; McCabe et al., 2001; Paciorek et al., 2002; Wang et al., 2006a) show regional changes that would be consistent with a northward shift of the winter storm track. Some of these studies relate these changes to inter-annual variability in atmospheric circulation patterns such as the North Atlantic Oscillation. Partial spatial and temporal sampling of such variability would make any resulting trend sensitive to the interval or area considered. We therefore restrict our discussion to the difference in trends from different data sources and make no comment about the size of any real trend in global marine wind speed.

near-surface winds from numerical weather prediction models run in reanalysis mode provide a somewhat independent measure of circulation strength to assess trends in adjusted ship wind speed. In this study, we compare co-located reanalysis and ship data sets and discuss inhomogeneity issues for both sources of marine winds.

Data sources for the ship observations, ship metadata, and reanalysis model output are described in Section 2, along with the definition of well-sampled areas for each analysis and the description of the wind method indicator. The selection of the study period, the analysis methods, and the adjustments for individual ship wind speeds are described in Section 3. Section 4 describes the results, showing the impact of the adjustments on inter-decadal trends and the comparison of trends in ship winds of each method type and in reanalysis winds. We discuss the results and potential for improvements to marine wind data in Section 5. Conclusions follow in Section 6.

\section{Data}

\subsection{ICOADS ship data}

This study uses 1950-2004 data from the ICOADS Release 2.2 collection of individual marine reports. The reports came from ship meteorological logbooks, and/or, 
beginning in 1966, transmissions by ship radio and the global telecommunications system (GTS). Many historical reports came to ICOADS from various international archives; a code for the source archive (known as a 'deck') is saved in each ICOADS report. Where reports were available from more than one source, a duplicate detection and elimination procedure was used (Slutz et al., 1985). The more complete and better qualityassured logbook data took precedence over GTS data.

The ICOADS contains reports from VOS and other marine platforms. Only VOS data are considered in this paper (ICOADS Platform Type $\leq 5$ ). The VOS reports come from many different types of ship, ranging in size from small fishing and research vessels to large container ships and tankers (Kent et al., 2007). Several different types of instrumentation are used by these ships and observational practice is variable (Thomas et al., 2005). ICOADS standard trimming limits for wind speed are used in this study, thereby excluding values more than 3.5 standard deviations from monthly normals for the location.

ICOADS contains some limited metadata about the source of the observation, including the ship's radio callsign (or buoy WMO number), if known, and a wind indicator flag, which indicates whether the wind was estimated or measured (Section 2.2). The ship's radio callsign appears in the ICOADS reports beginning in 1966, coinciding with the implementation of the GTS, although it is present in only a small proportion of reports in the first decade (Kent et al., 2007). It is a critical parameter for linking the observation to other metadata for the ship, as described in Section 2.3.

Monthly statistics are usually calculated from the ICOADS data using observations within latitudelongitude grid boxes. Owing to the spatial and temporal variations in the availability of data (due, for example, to VOS using preferred shipping lanes), data are not always present in a grid box, for each month, over a period of time. Since we are interested in temporal trends and averages, we want to include in our analysis only those areas with data that are reasonably well represented over time. At a minimum, we define well-sampled grid boxes as those that have data for at least $75 \%$ of the total number of months in the time period of interest.

For analyses where multiple time series are compared, we define well-sampled as those grid boxes that have data for each variable in the same month (i.e. co-located monthly means), for $75 \%$ of the months in the time period of interest. For measured winds, there are only sufficient data and metadata for the years 1982-2002. For analyses which compare observations for the full period and include also anemometer observations for the later period (e.g. Figures 7 and 8) we required $75 \%$ of months sampled for the whole period (e.g. for estimated, means for the later period. Measured ship winds are not used if an estimate of anemometer height is not available for a particular report, so well-sampled in this case also or all-data) and in addition $75 \%$ of co-located monthly

requires the availability of height metadata for measured winds.

For an analysis of trend at individual grid boxes over the relatively short period 1982-2002 (Figure 9), the criteria for well-sampled were more stringent. In this case, for the 21-year period 1982-2002, each grid box, for each method type, was required to have co-located data for at least $9(75 \%)$ months of each year, in addition to $75 \%$ of months over the full period.

Inset maps (Figures 4, 6, 7, and 8) show the geographical regions where the sampling criteria were met for the particular combination of data types and periods being considered. The analysis areas change slightly from map to map, but are broadly similar. They show the familiar, frequently sampled, regions from ICOADS, concentrated in the Northern Hemisphere and the major shipping lanes.

\subsection{Wind observation method}

Within the ICOADS the method of wind observation, if known, is given by the wind speed indicator (WI) flag, which indicates the original units (knots, $\mathrm{ms}^{-1}$, or Beaufort Force) and whether the wind was estimated or measured. Table I lists the possible values for the WI flag, and their assignment for this study into two observation method groups, estimated and measured. Figure 1(a) shows the composition of the wind data in the ICOADS for the period 1950-2004 by a cumulative count for each observation method grouping assigned using the WI flag. There is one ambiguous value, $\mathrm{WI}=6$, which indicates the method is estimated or unknown (Slutz et al., 1985). This ambiguity resulted from the different ways in which some of the earlier source archives saved the original wind method information: 'blank' for estimated, 'zero' for measured, with no allowance for a 'missing' indicator (Cardone et al., 1990). For this study, we have assumed that most of the ambiguously flagged

Table I. Wind Speed Indicators (WI) in ICOADS. WI shows the original units and the method by which the wind speed was originally recorded or as coded in source archives. ICOADS wind speeds are stored to $0.1 \mathrm{~ms}^{-1}$.

\begin{tabular}{|c|c|c|}
\hline WI & Description (units, method) & $\begin{array}{c}\text { Grouping } \\
\text { for } \\
\text { analysis }\end{array}$ \\
\hline 0 & Metre per second, estimated & Estimated \\
\hline 1 & Metre per second, measured & Measured \\
\hline 2 & Estimated (original units unknown) & Estimated \\
\hline 3 & Knot, estimated & Estimated \\
\hline 4 & Knot, measured & Measured \\
\hline 5 & $\begin{array}{l}\text { Beaufort force (conversion of original } \\
\text { data, or based on documentation) }\end{array}$ & Estimated \\
\hline 6 & $\begin{array}{l}\text { Estimated (original units unknown) } \\
\text { OR unknown method }\end{array}$ & Estimated \\
\hline 7 & Measured (original units unknown) & Measured \\
\hline 8 & $\begin{array}{l}\text { High resolution measurement (e.g. } \\
\text { hundredths of a metre per second) }\end{array}$ & Measured \\
\hline Missing & $\begin{array}{l}\text { Wind indicator blank so method and } \\
\text { units unknown }\end{array}$ & Not used \\
\hline
\end{tabular}



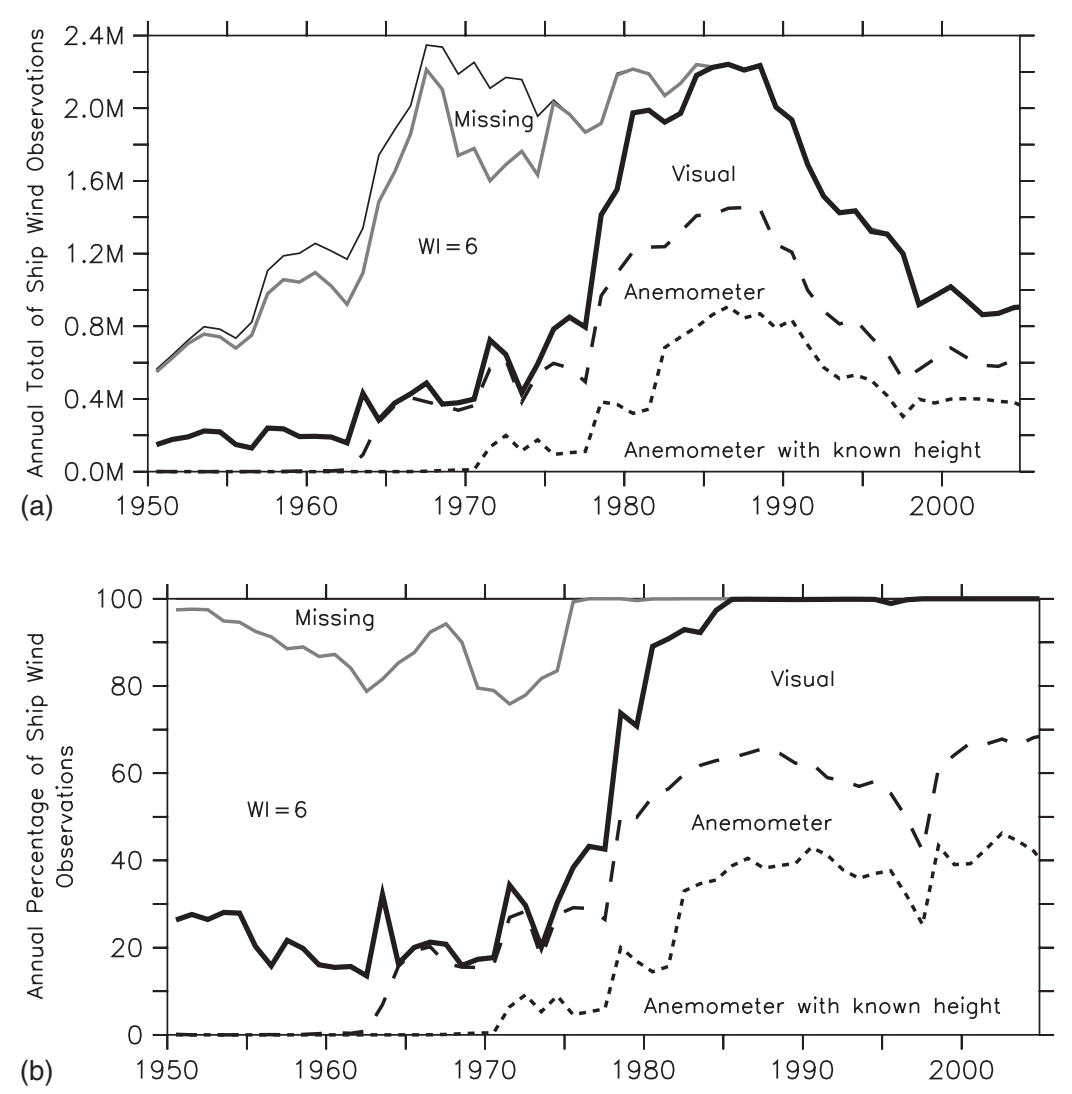

Figure 1. a) Time series of annual numbers of global VOS wind reports in ICOADS, 1950-2004, by observation method as indicated by the ICOADS wind indicator WI, plotted cumulatively, for: anemometer-measured only with known anemometer height (dotted); all anemometer-measured (dashed); visually estimated (not including WI $=6$, thick solid); WI $=6$ (grey); WI $=$ missing (solid); b) as a) but as a percentage of the total number of ship reports with wind observations.

reports were estimated, and assigned all data with this flag to the estimated group. Some measured reports are present in this category, as noted by Cardone et al. (1990) and confirmed by inspection of wind distributions from a limited number of source archives. However, the high proportion of reports in this category $(70-80 \%$ of all reports between 1950 and 1975, Figure 1(b)) means that it is impractical to exclude them from the analysis. The number of reports with this ambiguous flag drops to zero in the early 1980s. Figure 1 also shows the number and proportion of measured winds for which the anemometer height was identified (or could be estimated from fields such as platform height) (Section 2.3). The total number of VOS wind speed observations increased between 1950 and 1968 to about 2.4 million $\mathrm{yr}^{-1}$, and then remained at this level until about 1990 when numbers began to decline, to less than 1 million $\mathrm{yr}^{-1}$ by 2004 .

The observation method also varies spatially. Figure 2 shows the percentage of VOS wind speed reports that were estimated (including the ambiguous WI $=6$ category), in well-sampled $5^{\circ}$ grid boxes, averaged over three different periods: (1) 1950-1969, (2) 1970-1979, and (3) 1980-2004. In the period 1950-1969, almost all of the wind reports were estimated (Figure 2(a)). In the 1970s, measured wind speeds become more common, especially in the N. Pacific (Figure 2(b)). In the period 1980-2004, there were significant numbers of measured reports everywhere in the analysis area, particularly in the N. Pacific where most wind reports were measured (Figure 2(c)). The differences in method reflect the regional distributions of the recruiting countries of the VOS, as the observing method is usually prescribed by the recruiting country. Over time, more of the VOS were equipped with anemometers, including those reporting visually estimated winds.

\subsection{WMO No. 47 list of ship metadata, including} anemometer height

Since 1955, observational metadata for the VOS on instrumentation, recruiting country, ship name, and radio callsign, etc. are available in WMO Publication No. 47, the International List of Selected, Supplementary and Auxiliary Ships (henceforth Pub. 47), published annually or quarterly (Kent et al., 2007). New elements have been added over time: for example, platform height was introduced in 1968, anemometer height in 1970, and vessel type in 1995. In 1995, the platform height element was replaced by the barometer height. We assume that these are equivalent, following Kent et al. (2007), who found very small differences between platform height and barometer height in most cases. The metadata are indexed by year (or by quarter after 1998) and by ship callsign and can be matched to individual reports within the ICOADS using the callsign. 

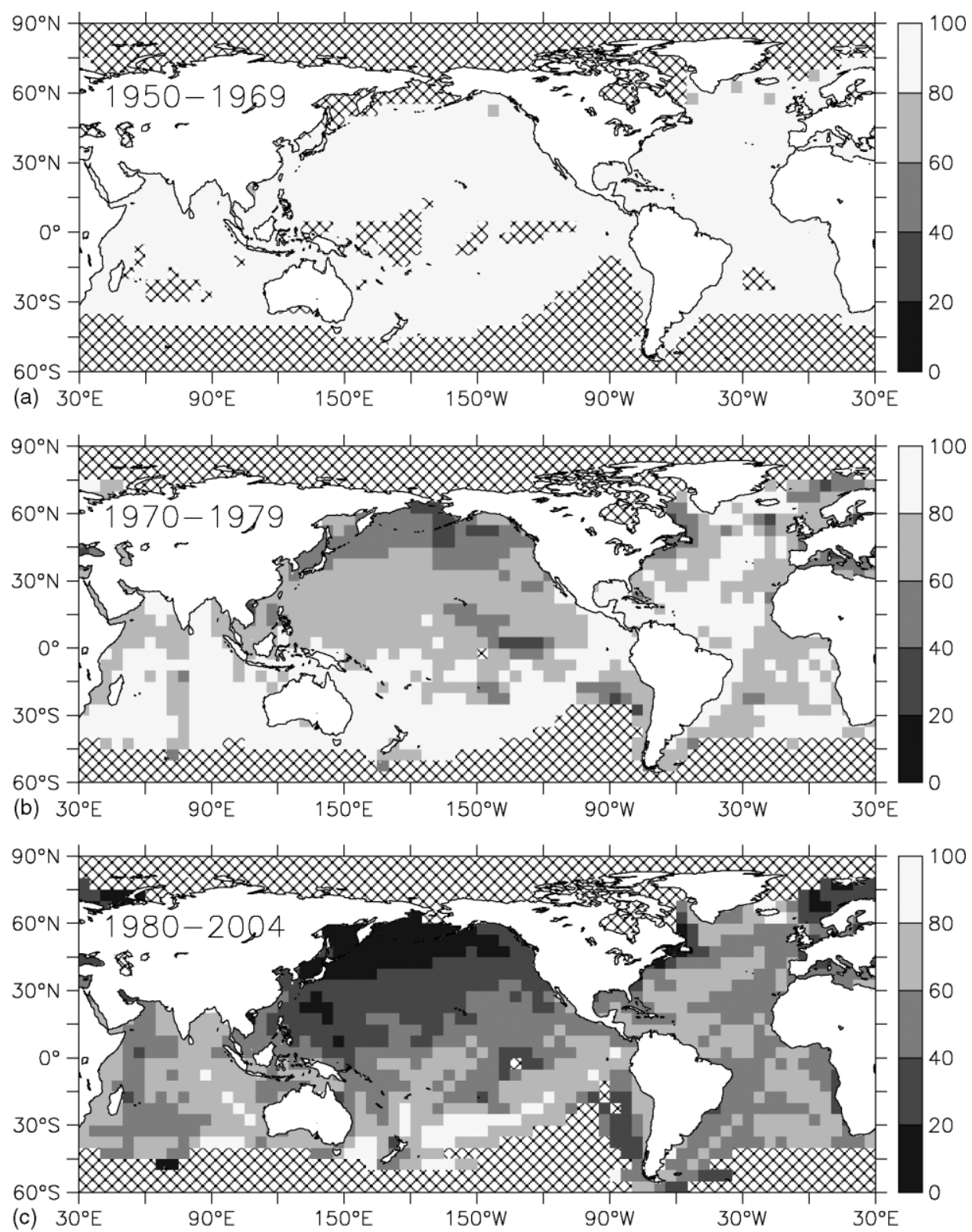

Figure 2. Maps of percentage of VOS wind speed reports in each well-sampled $5^{\circ}$ grid box that are visually estimated observations $(\mathrm{WI}=0,2$, 3, 5 and the ambiguous 'estimated or unknown' category, WI = 6), in each period: a) 1950-1969; b) 1970-1979; c) 1980-2004. Most of the remaining wind speed observations are known to be measured (see Figure 1). Well-sampled grid boxes for each period are those with data for at least $75 \%$ of the total number of months; the hatching indicates areas that were not well sampled.

We extended the amount of metadata available in two ways. Firstly, when a new metadata element is introduced, we copied the values for the new metadata elements back in time for each continuously reporting ship (identified by callsign and agreement in other selected metadata elements). Secondly, we extended the validity dates at the start and end of a ship's appearance in Pub. 47. This was to allow for either delays in metadata submission or periodic non-submission of metadata from some countries (Kent et al., 2007). For ships with platform (or later, barometer) height but not anemometer height metadata (less than $10 \%$ of the cases - see Kent et al., 2007), the anemometer height was estimated using the platform height plus $10-\mathrm{m}$. This was the typical anemometer minus platform height difference for an individual ship (Kent et al., 2007).
After application of these steps, anemometer heights for individual ships were identified for only about onethird of the measured wind reports in the 1970s, increasing to two-thirds by 1982 (Figure 1(b)). The relatively low success of assignment of measurement height in the 1970s and earlier is partly due to lack of callsign information in many archived reports.

Figure 3 is a map of monthly mean anemometer heights for well-sampled (in terms of the availability of both wind speed data and accompanying anemometer height metadata) $5^{\circ}$ grid boxes, averaged over the period 1982-2002. This figure shows that wind measurement heights were greatest (over $35 \mathrm{~m}$ ) along the major shipping lanes in the N. Pacific, with average anemometer heights of 30-35 m over most of the N. Pacific, in the South China and Philippine Seas, and along the main 


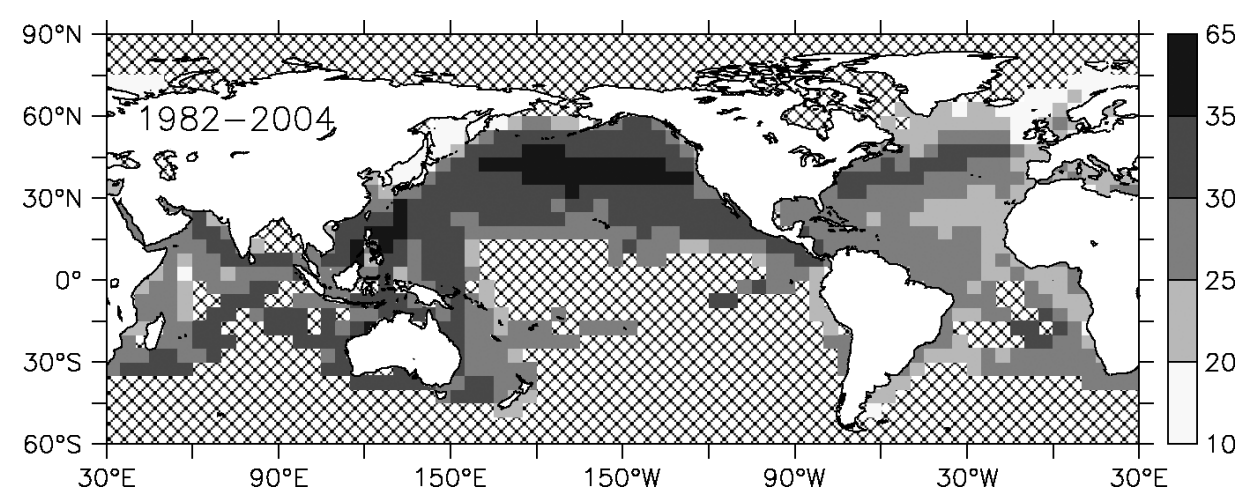

Figure 3. Map of average of monthly mean anemometer height $(\mathrm{m})$ for $1982-2004$, for well-sampled $5^{\circ}$ grid boxes. Well-sampled grid boxes are those with data for at least $75 \%$ of the total number of months over the 23 -yr period (i.e. 207 monthly means); the hatching indicates areas that were not well sampled over the period.

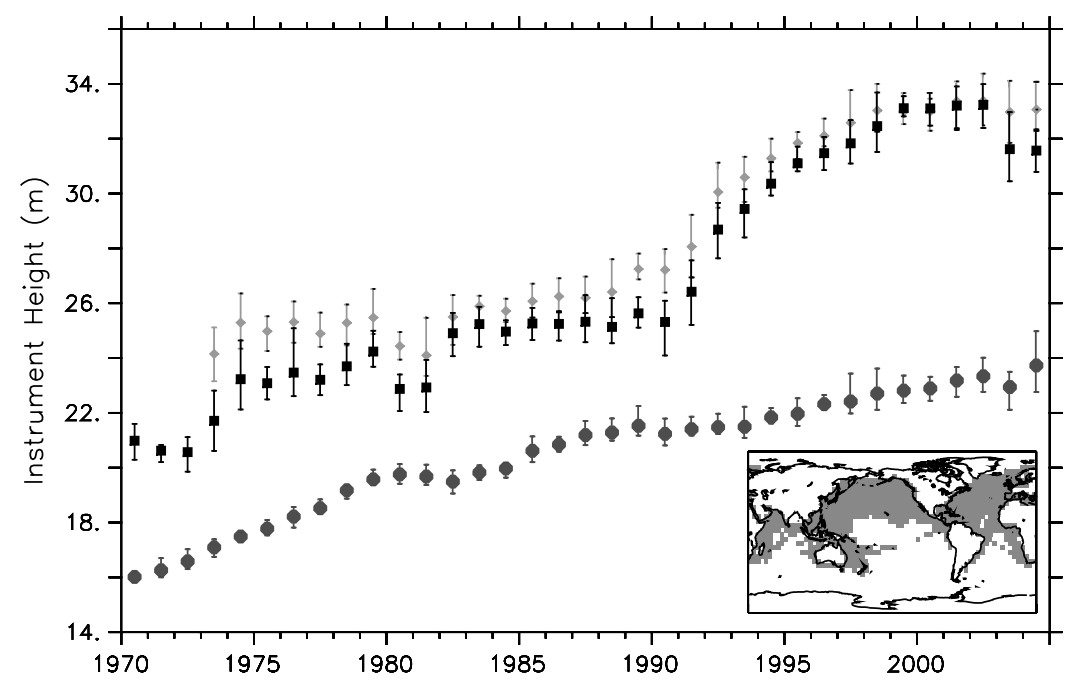

Figure 4. Time series of annual averages of monthly mean anemometer (black squares) and platform (dark grey circles) heights (in $\mathrm{m}$ ), averaged over well-sampled $5^{\circ}$ grid boxes 1970-2004 (area shown in map inset). Bars represent the range of monthly mean height in each year. Anemometer and platform heights are for all available data, whether reporting estimated or measured winds, and without the requirement that both fields be present for each report. Also plotted is the value of platform height $+10-\mathrm{m}$ for those reports for which both anemometer and platform height were available (light grey diamonds).

shipping lanes of the N. Atlantic. Lower anemometer heights were more common in regions where reports from smaller vessels predominated (Kent et al., 2007).

Figure 4 shows time series of the annual averages of spatially averaged (over all well-sampled $5^{\circ}$ grid boxes) gridded monthly anemometer and platform (or barometer) heights, for the period 1970-2004. The gridded monthly mean heights were calculated using all available ship reports, whether or not the wind was measured, and without the requirement that both fields be present for each report. This figure shows that the average anemometer height increased from about $21 \mathrm{~m}$ in 1970 to about $32 \mathrm{~m}$ by 2002, with the greatest increases in the early 1990s. The average platform height (calculated from individual platform heights whether or not there was a corresponding anemometer height) rose steadily over the period, from $16 \mathrm{~m}$ in 1970 to $24 \mathrm{~m}$ by 2004 . Also plotted is the platform height plus $10-\mathrm{m}$, for those reports for which both anemometer and platform (or barometer) heights were available. This shows that the approximation, that the anemometer was typically about 10 -m higher than the platform height, is reasonable (our calculations show that small differences in actual anemometer height would have little overall impact on trend). This simple approximation allows us to include about $10 \%$ extra reports from anemometers during the 1970s and 1980s (Kent et al., 2007), which significantly increases the analysis area.

\subsection{NCEP-NCAR and ECMWF reanalysis (NCEPR and ERA40) winds}

We compare time series of spatially averaged observed ship winds in ICOADS and near-surface (10-m) reanalysis model output from both the National Centers for Environmental Prediction - National Center for Atmospheric Research (NCEP-NCAR) Reanalysis (NCEPR, Kalnay et al., 1996; Kistler et al., 2001) and the European Centre for Medium Range Weather Forecasting (ECMWF) Reanalysis (ERA40, Uppala et al., 2005). Although the reanalyses are free of the inhomogeneities 
due to changes in model resolution and physics, inhomogeneity in the observational database can cause artificial changes over time (Hines et al., 2000; Kistler et al., 2001; Sterl, 2004). However, these effects are expected to be small after the introduction of global satellite data in 1979. Swail et al. (1999) found small differences in trends in NCEPR winds over the last four decades, compared to homogeneous observations and pressuretriangle-derived winds from coastal land stations, at a limited number of locations in the mid-latitudes of the $\mathrm{N}$. Pacific and N. Atlantic. The comparison data indicated a decreasing trend, while the NCEPR winds showed almost no trend, at the locations analysed.

Comparisons of the NCEPR and ERA40 near-surface winds with satellite, buoy, research-vessel and land station winds showed that reanalysis near-surface winds were biased low, particularly in tropical latitudes and for high wind speeds (Swail and Cox, 2000; Smith et al., 2001; Kubota et al., 2002; Caires and Sterl, 2003; Goswami and Sengupta, 2003; Wu and Xie, 2003; Yuan, 2004; Jiang et al., 2005).

For each data set, 6-hourly fields of zonal and meridional near-surface wind components, on the reanalysis grid, were combined to form 6-hourly scalar-mean wind speeds, which were then averaged to give monthly mean scalar values. These monthly means were then re-gridded, using linear interpolation, onto the same $5^{\circ}$ grid boxes used in this study.

The data sets assimilated into both reanalyses are similar. However, special sensor microwave imager (SSM/I) and ERS scatterometer near-surface $(10-\mathrm{m})$ wind data are assimilated into the ERA40, beginning in 1987 and 1993 respectively, but not into the NCEPR. QuikScat nearsurface winds are not assimilated into either reanalysis. Both reanalysis models assimilate surface marine data from ICOADS, however profile information such as rawinsonde observations have significantly more impact on the analysis (Kistler et al., 2001). The NCEPR assimilates all marine winds as if at 10-m, whereas the ERA40 assimilates both measured and estimated ship winds at anemometer height if known, or at a more representative height of $25 \mathrm{~m}$ otherwise (Uppala et al., 2005). Neither reanalysis is truly independent of ICOADS. However, we expect that the large amount of other observational data assimilated near the surface and above will constrain the reanalyses and limit the influence of a possible spurious trend in the ICOADS ship wind data.

Reanalysis data for individual grid boxes are included in the analysis only for those months with ship data (i.e. co-located data) and only for those grid boxes considered well sampled with regard to ship data.

\section{Analysis methods and adjustments to individual ship windss}

3.1. Selection of analysis periods and description of analysis methods

This study presents ICOADS ship wind data for the period 1950-2004, however the impact of adjustments and the differences in adjusted-wind-speed trends are assessed for the period 1958-2002. The International Geophysical Year (July 1957-December 1958), considered the start of the modern observing system, was accompanied by an increase in observation numbers. Hence, the ERA40 reanalysis product is available beginning mid-1957. We therefore apply the wind adjustments from 1958 onwards and note that earlier wind speed observations require further analysis.

In 2002, a version of the logging software 'TurboWin' (http://sciamachy-validation.org/onderzk/applied/ turbowin/turbowin.html, accessed 19 September 2006), used by observers on some ships to code observations into the required transmission format, began adjusting the wind speed from measurement height to $10-\mathrm{m}$ before transmission (Kent et al., 2007). As there is limited metadata available to determine which wind reports have been height adjusted, this study did not analyse data beyond 2002.

The trends in measured winds compared to other winds are examined in the latter part (1982-2002) of the period only, due to the relatively low proportion of measured wind reports with sufficient metadata prior to that time. All wind reports that could not be adjusted (either due to a missing method flag or a measured wind with unknown anemometer height) were excluded from the comparisons, as were the few wind reports from anemometers at greater than $50 \mathrm{~m}$ (to reduce possible contributions from offshore platforms incorrectly identified in ICOADS as ships).

Individual scalar wind speeds (denoted $u$ ) were used to calculate $5^{\circ}$-gridded monthly mean scalar wind speeds (denoted $U$ ). In order to study time series representing as large a geographical area as possible, the gridded monthly mean winds, $U$, were spatially averaged over all grid boxes that were sufficiently well sampled (as defined in Section 2.1). Annual means of the monthly spatially averaged scalar wind speeds are denoted $\langle U\rangle$.

Monthly gridded winds were calculated separately for wind reports of each method type: estimated and measured and for both estimated and measured together (denoted all-data), and for each of those, separately for original and adjusted values. The requirement for a known anemometer height, for a measured wind to be included in the analysis, meant that the alldata category prior to 1970 contains estimated winds almost exclusively. Monthly values were also calculated separately for each wind type observed by day and by night, although most results presented in this study are for day and night reports together.

The various wind types are denoted with subscripts as follows: $A$ for all unadjusted VOS wind speeds; $A 10$ for all adjusted VOS wind speeds; $E$ for estimated wind speeds; $E L$ for estimated wind speeds adjusted following Lindau (1995a); $M$ for measured wind speeds; and M10 for height-adjusted measured wind speeds. Monthly or annual climatological values of the reanalysis nearsurface wind speeds, denoted NCEPR and ERA40 as appropriate, are compared to the observed values, using 
Table II. Annual mean wind speeds and trends in the periods 1958-2002, 1958-1981, and 1982-2002, for spatially averaged (over all well-sampled $5^{\circ}$ grid boxes, see Section 2.1 ) monthly mean ship and reanalysis winds, with original and adjusted ship winds categorized by method of observation (Section 3). Uncertainty estimates represent one standard error. Percentage trends are relative to the annual mean at the start of the period. See Figure 7 for corresponding time series and inset map of analysis area.

\begin{tabular}{|c|c|c|c|c|c|c|c|c|c|}
\hline \multirow{2}{*}{$\begin{array}{l}\text { Wind speed } \\
\text { method } \\
\text { Year }\end{array}$} & \multicolumn{3}{|c|}{$\begin{array}{l}\text { Annual mean } \\
\left(\mathrm{ms}^{-1}\right)\end{array}$} & \multicolumn{3}{|c|}{$\begin{array}{c}\text { Trend in } \\
\text { annual mean }\left(\mathrm{ms}^{-1} \text { decade }^{-1}\right)\end{array}$} & \multicolumn{3}{|c|}{$\begin{array}{l}\text { Trend in } \\
\text { annual mean }\left(\% \text { decade }^{-1}\right)\end{array}$} \\
\hline & 1958 & 1982 & 2002 & $1958-2002$ & $1958-1981$ & $1982-2002$ & $1958-2002$ & $1958-1981$ & $1982-2002$ \\
\hline \multicolumn{10}{|l|}{ Unadjusted } \\
\hline All $<U_{A}>$ & 6.4 & 6.8 & 7.5 & $0.29 \pm 0.01$ & $0.14 \pm 0.02$ & $0.36 \pm 0.01$ & $4.6 \pm 0.2$ & $2.2 \pm 0.3$ & $5.2 \pm 0.2$ \\
\hline Estimated $<U_{E}>$ & 6.4 & 6.6 & 7.3 & $0.23 \pm 0.01$ & $0.06 \pm 0.02$ & $0.40 \pm 0.02$ & $3.6 \pm 0.2$ & $1.0 \pm 0.3$ & $6.1 \pm 0.3$ \\
\hline $\begin{array}{l}\text { Measured }<U_{M}> \\
\text { Adjusted }\end{array}$ & - & 7.3 & 7.8 & - & - & $0.32 \pm 0.02$ & - & - & $4.4 \pm 0.3$ \\
\hline All $<U_{A 10}>$ & 6.6 & 6.8 & 7.3 & $0.18 \pm 0.01$ & $0.06 \pm 0.01$ & $0.31 \pm 0.02$ & $2.7 \pm 0.2$ & $0.9 \pm 0.2$ & $4.6 \pm 0.3$ \\
\hline Estimated $<U_{E L}>$ & 6.6 & 6.8 & 7.5 & $0.22 \pm 0.01$ & $0.06 \pm 0.02$ & $0.38 \pm 0.02$ & $3.3 \pm 0.2$ & $0.9 \pm 0.2$ & $5.7 \pm 0.3$ \\
\hline $\begin{array}{l}\text { Measured }<U_{M 10}> \\
\text { Reanalysis }\end{array}$ & - & 6.8 & 7.1 & - & - & $0.20 \pm 0.02$ & - & - & $2.9 \pm 0.3$ \\
\hline $\mathrm{NCEPR}<U_{N C E P R}>$ & 6.3 & 6.3 & 6.4 & $0.01 \pm 0.01$ & $-0.03 \pm 0.01$ & $0.06 \pm 0.01$ & $0.1 \pm 0.1$ & $-0.5 \pm 0.2$ & $1.0 \pm 0.2$ \\
\hline ERA40 $<U_{E R A 40}>$ & 6.1 & 6.2 & 6.3 & $0.06 \pm 0.01$ & $0.05 \pm 0.01$ & $0.05 \pm 0.02$ & $0.9 \pm 0.2$ & $0.8 \pm 0.2$ & $0.8 \pm 0.3$ \\
\hline
\end{tabular}

the same analysis areas and months as for the observed winds.

Linear trends in the time series of annual means of spatially averaged data were calculated for each wind type (shown in Figure 7) from the slopes of ordinaryleast-squares linear regression lines fitted to the data. The trends presented in Table II apply to the spatially averaged data sets, for the full period 1958-2002 and two sub-set periods: 1958-1981 and 1982-2002. In addition trends were calculated for each well-sampled $5^{\circ}$ grid box for the period 1982-2002, from the annual averages of gridded monthly means.

The purpose of looking at the linear trends is not to attach much significance to the actual values of the trends or to make conclusions about the significance of the trends, since the periods are relatively short, but to assess the differences in the trends in each wind type e.g. measured compared to estimated, original compared to adjusted, ship compared to reanalysis trends.

\subsection{Adjustment to estimated ship winds}

Individual estimated wind speeds, $u_{E}$, were adjusted using the equivalent values of Lindau (1995a, 2003) to remove biases arising from use of the original Beaufort equivalent scale (WMO1100). Kent and Taylor (1997) tested alternative scales using the criterion of homogeneity between estimated and measured monthly mean winds from the ICOADS, and found that the scale of Lindau (1995a) gave the best agreement in monthly mean $1^{\circ}$ area winds, for the period 1980-1990. The scale is non-linear, increasing the lighter winds and decreasing the stronger winds, with the crossover between Beaufort 5 and 6 , at about $11 \mathrm{~ms}^{-1}$. Figure 5(a) shows the Lindau adjustment for visually estimated winds, as a function of reported wind speed (one value for each Beaufort Force interval), and the 3rd order polynomial fit to those values. Following Thomas et al. (2005), the adjustment was made in the form of the third-order polynomial that interpolates between the midpoints of the Beaufort intervals; it was not used to extrapolate beyond the lower bound of Beaufort Force 12. Interpretation of estimated winds of Beaufort Force 12 is problematic as Force 12 has a lower bound only, of $33 \mathrm{~ms}^{-1}$ (64 knots). Estimated winds stronger than the Beaufort Force 12 lower bound were very rare and were excluded from this study. The magnitude of the adjustment ranges from +0.5 (at $6 \mathrm{~ms}^{-1}$ ) to $-3.5 \mathrm{~ms}^{-1}$ (at $30 \mathrm{~ms}^{-1}$ ).

Figure 5(b) shows the amount of the adjustment (adjusted minus original) for individual estimated wind speeds, averaged monthly for each $5^{\circ}$ grid box, then averaged over the well-sampled grid boxes for the period 1950-2002. Annual averages of the monthly values are also plotted. The adjustment increases the monthly mean, $U_{E}$ (because the majority of wind reports are less than $\left.11 \mathrm{~ms}^{-1}\right)$. The mean adjustment varies seasonally due to the variation in mean wind speed. Over the period 1950-2002, as $U_{E}$ increases, the magnitude of the average adjustment decreases slightly.

3.3. Adjustment to measured ship winds, for anemometer height

Individual measured wind speeds, $u_{M}$, were adjusted from the known anemometer height to the near-surface height of $10-\mathrm{m}\left(u_{M 10}\right)$ using a neutral logarithmic profile and a surface roughness length that varies with wind speed. The parameterization of Smith (1988) was used, but implemented with an improved numerical algorithm (Walmsley, 1988). The algorithm can account for atmospheric stability using the air minus sea temperature difference, but in this study, it was implemented for zero temperature difference, i.e. neutral stability. As examples of the magnitude of the adjustment, adjustment of moderate wind speeds from 20 to $10-\mathrm{m}$ requires a $5 \%$ reduction and from 30 to $10-\mathrm{m}$ an $8 \%$ reduction. 

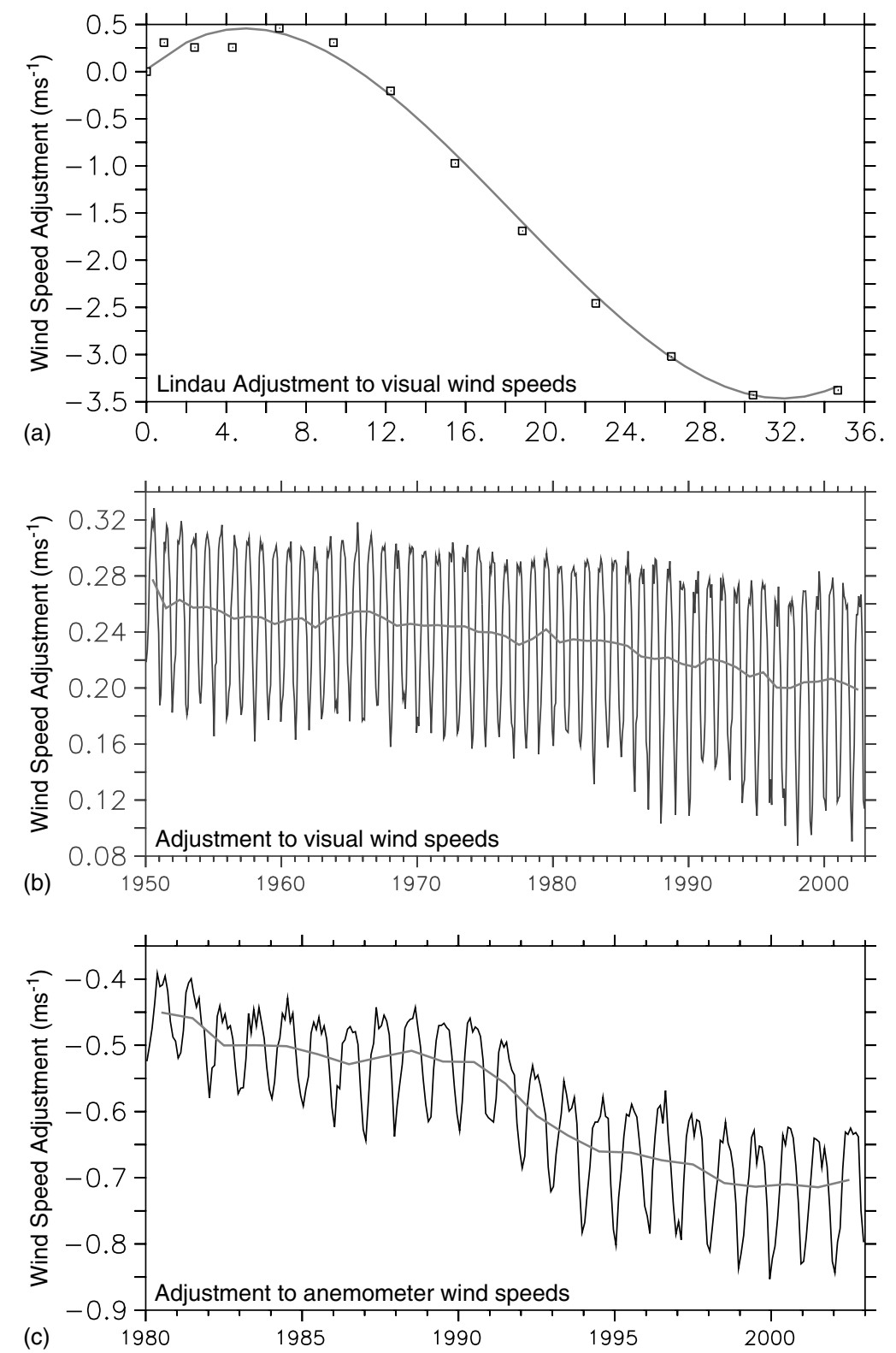

Figure 5. Amount of adjustment (adjusted - original wind speed) for estimated and measured wind speeds: a) Lindau adjustment for estimated winds as a function of the reported wind speed, with the $3^{\text {rd }}$ order polynomial best fit line; b) Monthly mean and annual mean adjustment applied to visually estimated winds, averaged over the region of well-sampled $5^{\circ}$ grid boxes for the period $1950-2002$; c) Same as b) for anemometer-measured winds, averaged over the region of well-sampled $5^{\circ}$ grid boxes for the period 1980-2002. Well-sampled grid boxes are those with data for at least $75 \%$ of the total number of months over the given time periods, in $\mathrm{b}$ and $\mathrm{c}$.

The approximation of neutral stability was made, in part, to avoid larger errors resulting from the surface layer appearing erroneously stable, due to observational air temperature errors (Berry et al., 2004); and in part, because many ships did not report sea temperature. Over the open ocean, the assumption of neutral stability in the surface layer is reasonably good, particularly for strong winds. However, in areas with strong temperature contrasts between the air and the water, when the surface layer is highly stratified, or highly unstable, it is less appropriate. In an 11-year study of 60 buoys, Mears et al. (2001) showed that the open-ocean surface layer was slightly unstable, and that adjusting winds using the assumption of neutral stability rather than the actual stability would cause a bias on the order of $-0.1 \mathrm{~ms}^{-1}$.
Any time-varying component of the bias would be significantly smaller than this and will therefore not affect the conclusions drawn in this paper.

Figure 5(c) shows time series of the adjustment (adjusted minus original) for individual measured wind speeds, gridded monthly, then averaged over wellsampled grid boxes, for the period 1980-2002. Annual averages of the spatially averaged monthly means are also plotted. The mean adjustment shows that measured winds are decreased, on average, when adjusted to 10-m, as most ship anemometers are higher than 10-m. Over that period, the average anemometer height increases by about 10-m, from 22 to $32 \mathrm{~m}$ (Figure 4), and the mean adjustment for measured wind speed changes from -0.45 to $-0.72 \mathrm{~ms}^{-1}$. 


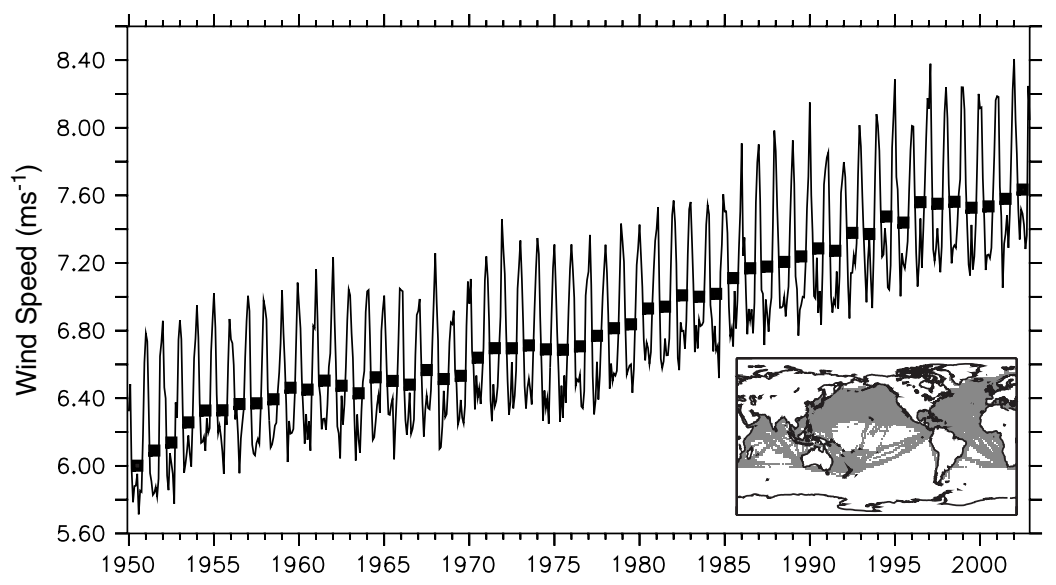

Figure 6. Time series of monthly mean wind speed (and annual averages of the monthly values) from ICOADS $2^{\circ}$ standard Monthly Summary Groups, averaged over all well-sampled $2^{\circ}$ boxes, 1950-2002 (area shown in map). Well-sampled grid boxes contain at least 477 monthly values over the $53-\mathrm{yr}$ period $(75 \%$ of total possible).

\section{Results: Differences in Wind Speed Trend, by Wind Method}

Gridded mean wind speeds, from the ICOADS $2^{\circ}$ Monthly Summary Groups, averaged over all well-sampled $2^{\circ}$ grid boxes over 1950-2002, indicate a steady and substantial increase in both monthly mean and annual mean scalar wind speeds over the last 50 years (Figure 6). Note that the standard ICOADS summaries are constructed from all ship wind speed reports within the 3.5 standard deviation trimming limits (Section 2.1), regardless of measurement method, and with no adjustments applied.

Figure 7 shows comparable time series of annual means of spatially averaged (over all well-sampled $5^{\circ}$ grid boxes) monthly mean wind speeds $(<U>$ ), for both original and adjusted-ship winds, both measured and estimated, and for reanalysis surface wind speeds. Table II gives the corresponding annual mean wind speeds in 1958, 1982, and 2002, and linear trends for the periods 1958-2002, 1958-1981, and 1982-2002, for each data source and sub-set. As in Figure 6, time series for annual mean (unadjusted) winds as reported $\left(<U_{A}>\right.$, $<U_{M}>$, and $<U_{E}>$ ), plotted in Figure 7(a), also show substantial increases. The mean all-data winds, $\left\langle U_{A}\right\rangle$, are calculated mostly from estimated reports in the early period and are therefore similar to $\left\langle U_{E}\right\rangle$. The annual mean measured winds, $\left\langle U_{M}\right\rangle$, are plotted beginning in 1982, when there are enough measured wind reports with known anemometer height over the large regions wellsampled by estimated wind reports. They are markedly stronger than either $\left\langle U_{E}>\right.$ or $\left\langle U_{A}>\right.$.

Figure 7(b) compares the annual mean all-data winds before and after adjustments: $\left\langle U_{A}\right\rangle$ and $\left\langle U_{A 10}\right\rangle$. The trend in the all-wind data is reduced from +0.3 to $+0.2 \mathrm{~ms}^{-1}$ decade $^{-1}$, following adjustments. Most of the change comes from the height adjustment of measured winds. Table II shows that trends in estimated winds are reduced only slightly by use of the revised Beaufort equivalent scale.

Figure 7(c) shows time series of the annual mean adjusted winds, $<U_{A 10}>,<U_{M 10}>$ and $<U_{E L}>$, and of the annual mean reanalysis winds (for colocated data over the same analysis area), $\left\langle U_{N C E P R}\right\rangle$ and $\left\langle U_{E R A 40}>\right.$. In the early 1980s, the annual mean adjusted ship winds, $\left\langle U_{M 10}>\right.$ and $\left\langle U_{E L}>\right.$, agree fairly well, but subsequently $\left\langle U_{E L}\right\rangle$ increases faster than $\left\langle U_{M 10}\right\rangle$ and the bias returns, this time with $<U_{E L}>$ greater than $<U_{M 10}>$. There is a substantial difference in ship wind trends before and after about 1982. Prior to that year, trends are small. After 1982, the 21-year trends for annual mean winds are $0.2 \mathrm{~ms}^{-1} \mathrm{decade}^{-1}\left(3 \% \mathrm{decade}^{-1}\right)$ for adjusted measured winds $\left\langle U_{M 10}>\right.$, and $0.4 \mathrm{~ms}^{-1}$ decade $^{-1}\left(6 \% \mathrm{decade}^{-1}\right)$ for adjusted estimated winds $\left\langle U_{E L}>\right.$.

Comparable values for the annual mean ERA40 reanalysis winds, $\left\langle U_{E R A 40}>\right.$, show a much lower trend over the full period (1958-2002), only about $0.06 \mathrm{~ms}^{-1}$ decade $^{-1}$ (less than $1 \%$ decade $^{-1}$ ), while the overall trend for $\left\langle U_{N C E P R}>\right.$ is near zero (Table II). Both reanalysis annual mean winds, $<U_{N C E P R}>$ and $<$ $U_{E R A 40}>$, are lower than the corresponding ship winds, and $\left\langle U_{E R A 40}\right\rangle$ is slightly lower than $\left\langle U_{N C E P R}\right\rangle$ (Table II). The adjusted all-data annual means in 1958 and 1982 are 5 and $8 \%$ higher, respectively, than the corresponding NCEPR values (Table II). The difference increases over the next two decades, as the ship winds increase faster than in the earlier period. By $2002,<U_{M 10}>$ is $11 \%$ greater and $<U_{E L}>$ is $17 \%$ (about $1 \mathrm{~ms}^{-1}$ ) greater than $\left\langle U_{N C E P R}\right\rangle$ (Table II). $<U_{A 10}>$ is $14 \%$ higher than $<U_{N C E P R}>$. Although $<U_{N C E P R}>$ and $<U_{E R A 40}>$ both show much smaller trends than the annual mean ship wind speeds, there are slight differences between the trends of each reanalysis in the period 1958-1981: < $U_{E R A 40}>$ increases slightly and $\left\langle U_{N C E P R}>\right.$ decreases slightly; then in the period 1982-2002, they both increase slightly at a similar rate. This difference in trends in the earlier period indicates that the reanalyses should be used with caution in studies of long-term variability.

Separate analysis of daytime and nighttime data reveals interesting changes over time. Figure 8 shows the difference between averages of daytime and nighttime reports, 

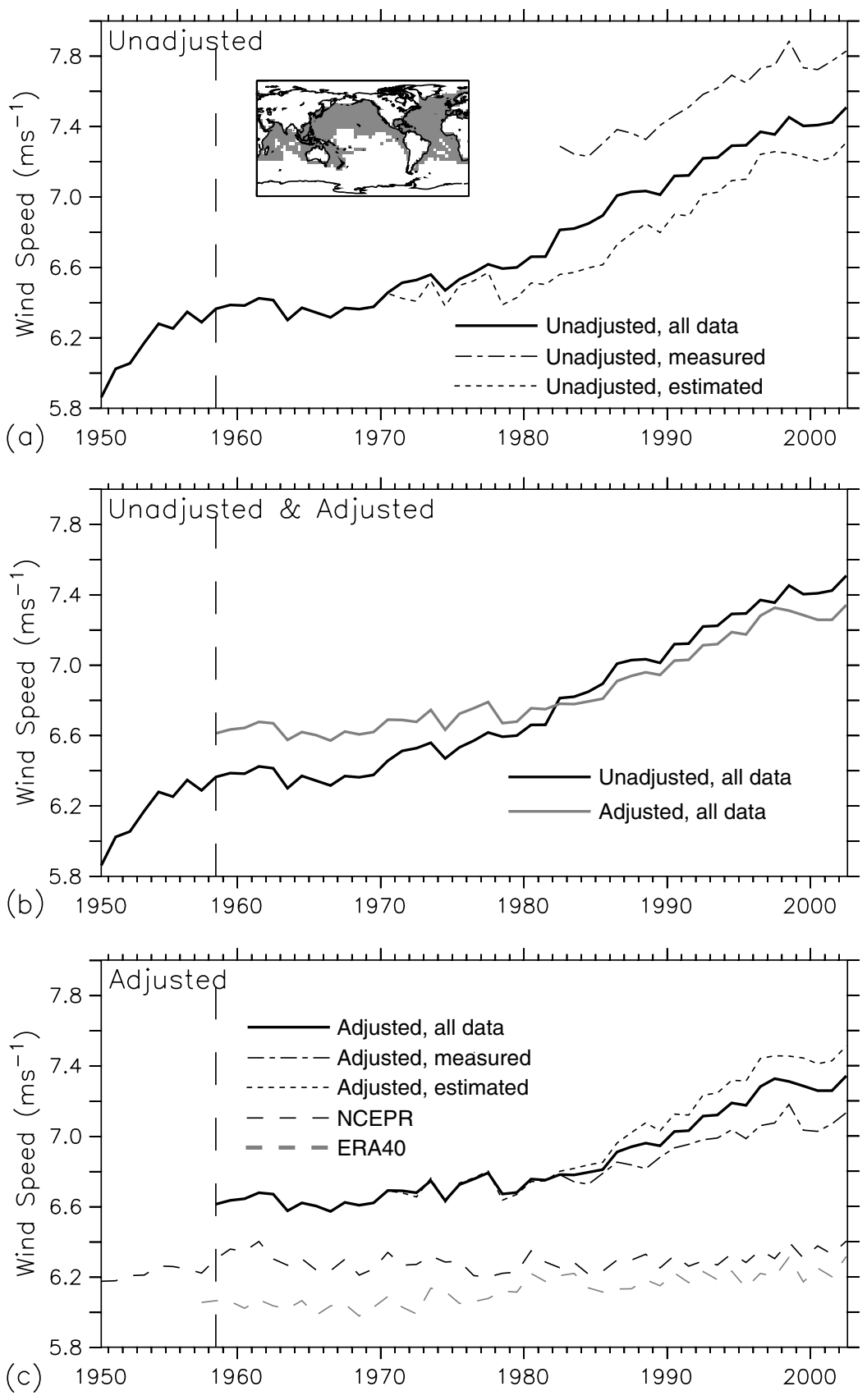

Figure 7. Time series of annual averages of monthly mean wind speeds $\left(\mathrm{ms}^{-1}\right)$, averaged over well-sampled $5^{\circ}$ grid boxes (see inset map) for unadjusted, adjusted and reanalysis wind speeds, 1958-2002 (except 1950-2002 (unadjusted and NCEPR) and 1982-2002 (measured)): a) unadjusted ship wind speeds: all-data $\left\langle U_{A}\right\rangle$, estimated $\left\langle U_{E}\right\rangle$, and measured $\left\langle U_{M}\right\rangle$; b) all-data unadjusted $\left\langle U_{A}\right\rangle$ and adjusted $\left\langle U_{A 10}\right\rangle$; c) adjusted ship wind speeds and reanalysis 10 -m winds: all-data $\left\langle U_{A 10}\right\rangle$, estimated $\left\langle U_{E L}\right\rangle$, measured $\left\langle U_{M 10}\right\rangle$, NCEPR $\left\langle U_{N C E P R}\right\rangle$ and ERA40 $\left\langle U_{E R A 40}\right\rangle$. See also Table 2. Well-sampled grid boxes are those with co-located estimated and all-data winds (present in the same months) for at least $75 \%$ of the total number of months in the 53-yr period, 1950-2002, and have co-located measured and estimated data for at least 75\% of the months in the 21-yr period, 1982-2002.

separately for $<U_{E L}>$ and $<U_{M 10}>$. The day - night difference for $\left\langle U_{E L}>\right.$ is initially large, about $0.3 \mathrm{~ms}^{-1}$ during the 1960s and 1970s, but it gradually decreases in the $1980 \mathrm{~s}$ and $1990 \mathrm{~s}$, to $0.1 \mathrm{~ms}^{-1}$ by 2002 . There is a smaller day - night difference for $\left\langle U_{M 10}\right\rangle$, around $0.1 \mathrm{~ms}^{-1}$ in 1982 but negligible difference by the end of the record.

Spatial patterns of the trends over the 21-year period 1982-2002, for each well-sampled $5^{\circ}$ grid box, in annual mean adjusted ship and reanalysis wind speeds, are mapped in Figure 9. The most notable feature is that both $U_{M 10}$ (Figure 9(a)) and especially $U_{E L}$ (Figure 9(b)) increase over almost all of the analysis region, whereas the reanalysis winds (Figure 9(c), (d)) tend to exhibit weaker trends of either sign. However $U_{M 10}$ does diminish in the Pacific at about $30^{\circ} \mathrm{N}$ and in northern latitudes of the North Atlantic.

The patterns in the trends in reanalysis winds, $U_{N C E P R}$ and $U_{E R A 40}$, are generally similar. Both reanalyses show large regions of decreasing winds $(-0.3$ to 


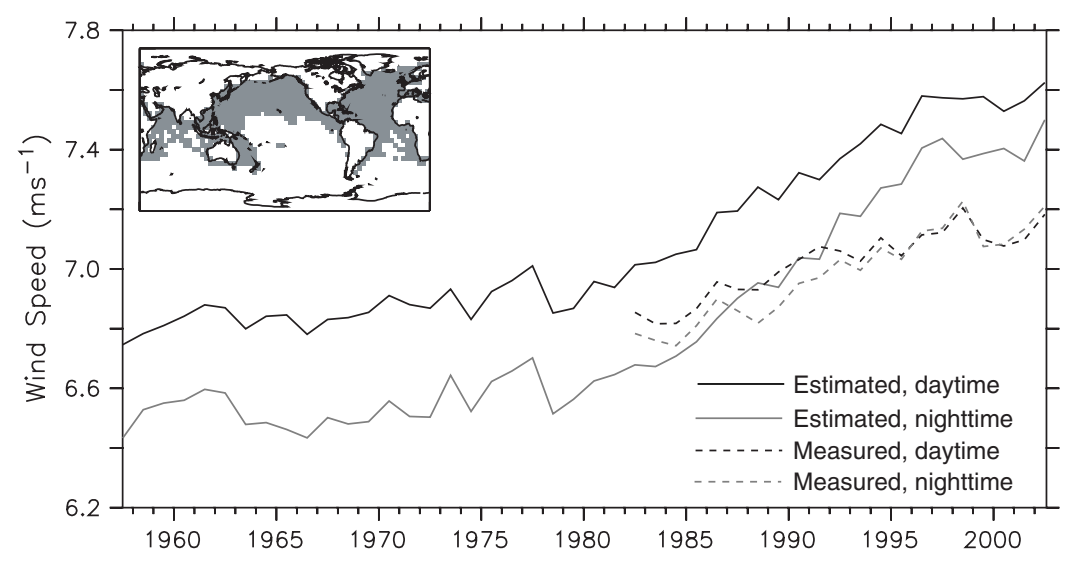

Figure 8. Time series of annual averages of monthly mean adjusted wind speeds $\left(\mathrm{ms}^{-1}\right)$, estimated, $\left\langle U_{E L}\right\rangle$, and measured, $\left\langle U_{M 10}\right\rangle$, averaged over well-sampled grid boxes (see inset map), but separately for co-located daytime and nighttime monthly means (for the period 1958-2002 for estimated and 1982-2002 for measured winds). The thresholds for numbers of monthly means are as for Figure 7.

$-0.1 \mathrm{~ms}^{-1} \mathrm{decade}^{-1}$ ) in the N. Pacific, over the midlatitudes, western and central sub-tropics, and western tropics. The negative trends are slightly stronger with the NCEPR than with the ERA40 winds. There are smaller areas of positive trend over the northern latitudes, the continental margins, and the eastern sub-tropics of the N. Pacific. In the N. Atlantic, the reanalysis model winds show generally positive trends (up to $+0.2 \mathrm{~ms}^{-1}$ decade $^{-1}$ ) over the mid-latitudes and the sub-tropics $\left(20^{\circ}-45^{\circ} \mathrm{N}\right)$, with an area of decreasing winds (to $-0.2 \mathrm{~ms}^{-1}$ decade $^{-1}$ ) over tropical and equatorial waters, and over northern latitudes $\left(50-60^{\circ} \mathrm{N}\right)$. The various ship wind types and reanalyses are consistent in showing increases over much of the Indian Ocean, although only some areas are well-sampled. The positive trends over the midlatitude and subtropical N. Atlantic and over the Indian Ocean are slightly stronger with the ERA40 than the NCEPR winds.

\section{Discussion}

The impact of the adjustments on $u_{E}$ and $u_{M}$, suggests that the conclusion of Cardone et al. (1990) that the increasing trend in ship winds could be largely explained by the shift toward more ships measuring rather than estimating the wind and by the increasing average height of anemometers, was correct up to the early 1980s. The 1958-1981 trend, in the all-data category, was reduced to $<+0.1 \mathrm{~ms}^{-1}$ decade $^{-1}$. The reduction in trend comes from adjusting the measured winds (Figure 7 shows the impact of the adjustment), as the trend in estimated winds was little changed by the Lindau adjustment. However, during the 1982-2002 period, the ship wind speeds strengthen at a greater rate than before, even after the adjustments.

The greater trend of $\left\langle U_{E L}>\right.$ compared to $\left\langle U_{M 10}\right\rangle$, after 1982, suggests that at least part of it is spurious. The decrease in the day - night difference in $U_{E L}$ since the early 1980s supports this idea. The larger day - night difference in $U_{E L}$ during the 1960s to early 1980s, of about $0.3 \mathrm{~ms}^{-1}$, could be explained if observers were underestimating the sea state, and hence the wind speed, at night (Kent et al., 1993). The day - night difference (order $0.1 \mathrm{~ms}^{-1}$ or less) shown by $U_{M 10}$ is more likely to be correct, which suggests that the much larger day - night difference in the visually estimated observations is spurious. This also suggests that the magnitude of the diurnal variation in wind speed over the open ocean found by Dai and Deser (1999) of order of $0.5 \mathrm{~ms}^{-1}$ may have been overestimated. The decrease in the diurnal difference over recent years could be explained if an increasing number of wind speeds reported by the observer as estimated were actually measured. This is a plausible explanation as an increasing number of ships carry anemometers. In addition, readouts displaying true wind speed (calculated automatically from the relative wind speed and navigational information) are increasingly common toward the end of the analysis period. Even if the observer does estimate the wind from visual observation of the sea state, there is an increasing likelihood of that estimate being influenced by knowledge of the measured wind speed at the anemometer height, which will be an overestimate of the 10-m wind speed.

Winds reported as estimated after the early 1980s, even with an unambiguous wind indicator flag, therefore probably contain a mixture of estimated and measured winds. Given that many of the reports in ICOADS in this period come from identifiable ships the problem seems tractable. Analysis of the characteristics of wind data from particular ships, or groups of ships, should indicate whether the reports are measured or estimated. Indicators could include the size of day night wind speed difference, the mean difference from nearby measured wind speeds or co-located model output, the shape of the wind speed distribution, the relationship with co-located wind wave observations, the known presence of an anemometer from metadata, or perhaps other characteristics. For those ships identified as misreporting the wind method, a simple adjustment based 


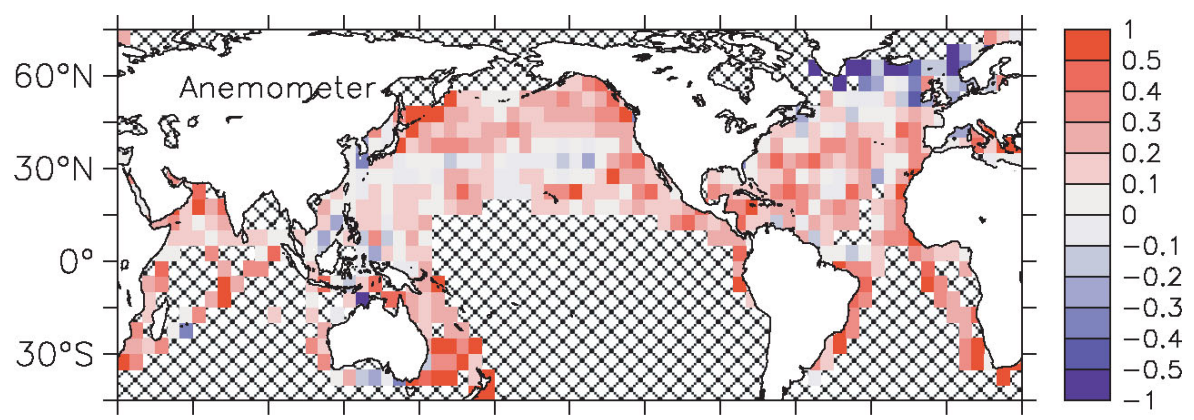

(a) $30^{\circ} \mathrm{E} \quad 90^{\circ} \mathrm{E} \quad 150^{\circ} \mathrm{E} \quad 150^{\circ} \mathrm{W} \quad 90^{\circ} \mathrm{W} \quad 30^{\circ} \mathrm{W} \quad 30^{\circ} \mathrm{E}$

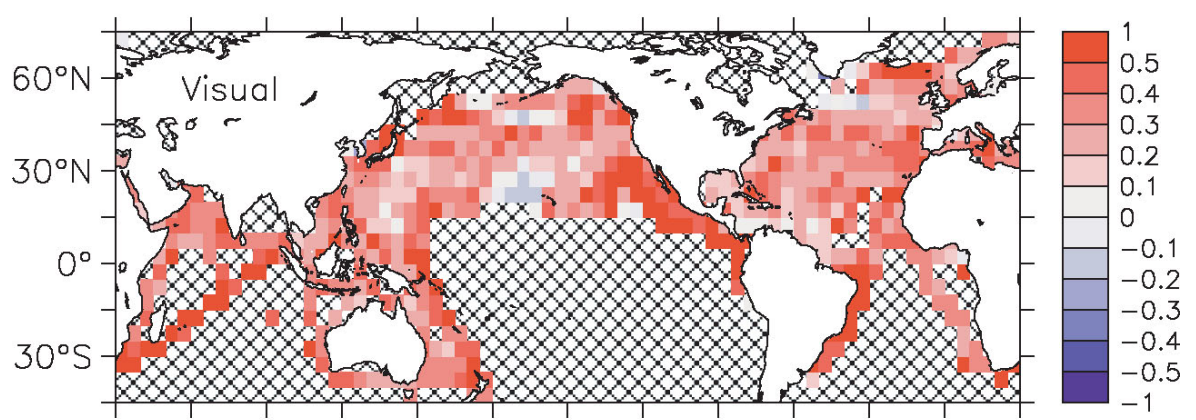

(b) $30^{\circ} \mathrm{E} \quad 90^{\circ} \mathrm{E} \quad 150^{\circ} \mathrm{E} \quad 150^{\circ} \mathrm{W} \quad 90^{\circ} \mathrm{W} \quad 30^{\circ} \mathrm{W} \quad 30^{\circ} \mathrm{E}$

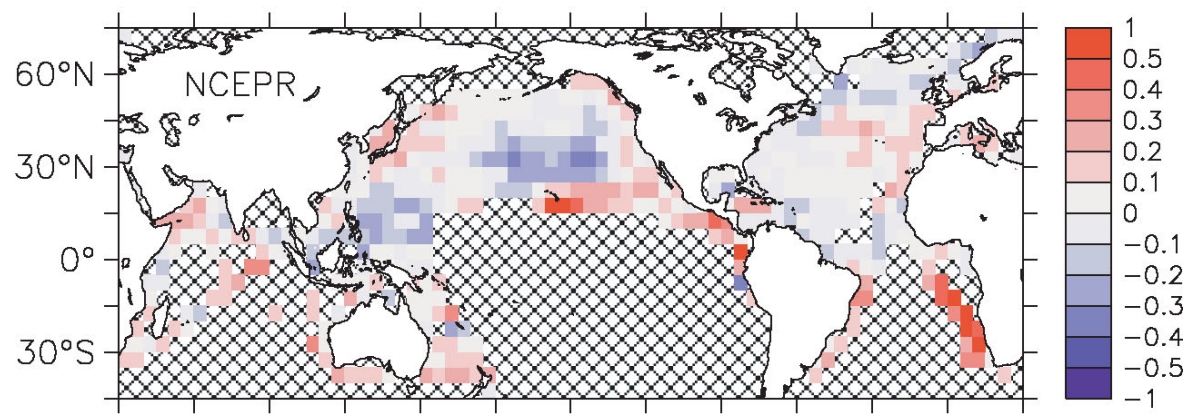

(c) $30^{\circ} \mathrm{E} \quad 90^{\circ} \mathrm{E} \quad 150^{\circ} \mathrm{E} \quad 150^{\circ} \mathrm{W} \quad 90^{\circ} \mathrm{W} \quad 30^{\circ} \mathrm{W} \quad 30^{\circ} \mathrm{E}$

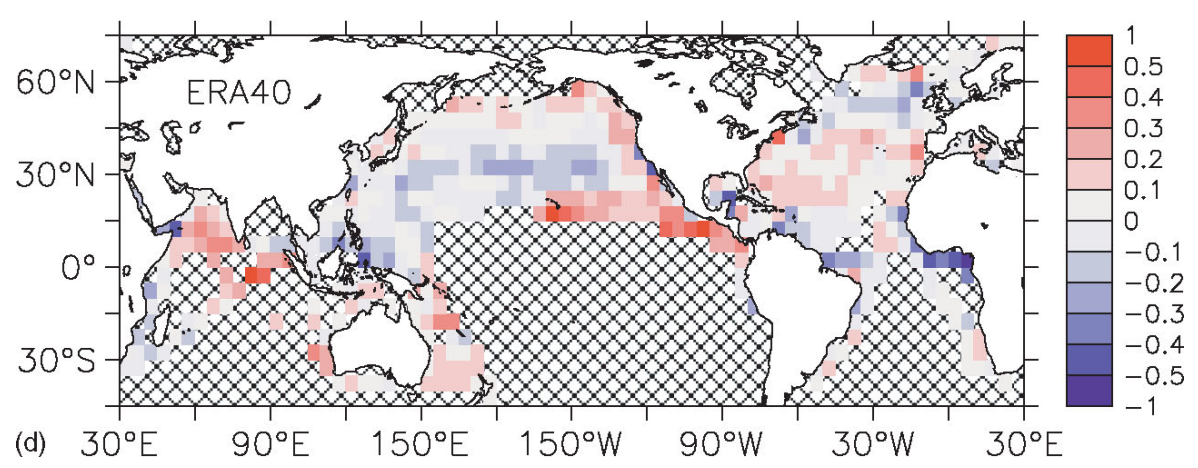

Figure 9. Map of linear trend $\left(\mathrm{ms}^{-1} \mathrm{decade}^{-1}\right)$ in annual mean adjusted ship and reanalysis $10-\mathrm{m}$ wind speeds over the period 1982-2002, for well-sampled $50^{\circ}$ grid boxes: a) height-adjusted anemometer-measured; b) Lindau-adjusted visually estimated; c) NCEPR reanalysis; and d) ERA40 reanalysis. Only monthly means with co-located data for each of the four data sources are used in the calculation. Well-sampled grid boxes are those with co-located data for $75 \%$ of the months of each year, as well as 75 of the total number of months in the $21-y r$ period (as in Figures 7 and 8).

on likely anemometer height (Kent et al., 2007) could be applied.

For those ships confirmed as typically making visual observations, the Beaufort Equivalent Scale should be reassessed. For example, Lindau (1995b) and Isemer (1995) suggested that separate Beaufort equivalent scales would be required for each country, since observing practices appeared to vary significantly from one recruiting country to another.

The positive temporal trend in annual mean heightadjusted measured winds, $\left\langle U_{M 10}>\right.$, is harder to explain. Factors to explore, which might cause a spurious temporal trend in measured ship winds, include: changes in instrumentation, changes in observing practise related to 
averaging period; a possible increasing tendency to report gusts; changes in flow distortion effects due to changes in distribution of ship types, speeds, or recruiting country; and a changing contribution of errors from calculation of the true wind as the mean ship operating speed increases (along with ship-size) over time. Gulev (1999) discussed the impact of incorrectly calculating the true wind from the ship relative wind, particularly in locations where the orientation of the main shipping lanes coincides with the prevailing wind direction. For ships travelling in one direction across the ocean and returning by a slightly different route, these differences would not necessarily average to zero.

The two reanalysis products considered here become more consistent with each other after satellite retrievals become available from 1979. Prior to this time, there is a time-varying inhomogeneity in at least one of the reanalysis products (Figure 7(c)). Although both ERA40 and NCEPR assimilate the ship winds (see Section 2.4) neither shows any obvious impact of the spurious wind speed increases. This may indicate that surface winds are well constrained by other data sources from the 1980s on, perhaps a result of the relative low weighting of surface observations (other than pressure) compared to radiosonde and satellite data. Despite the lower spatial resolution of NCEPR, $<U_{N C E P R}>$ is slightly stronger than $<U_{E R A 40}>$. Our study found a persistent and increasing difference between $\left\langle U_{M 10}\right\rangle$ and both $<$ $U_{E R A 40}>$ and $<U_{N C E P R}>$. Smith et al. (2001) found a persistent low bias in the NCEPR winds at all latitudes, compared to winds from research vessels in the early 1990s, which was attributed to an underestimation of the NCEPR pressure gradients.

Although it seems generally accepted that reanalysis near-surface winds are biased low, some part of the difference found in our study may be due to flow distortion over the ship. Ship winds in this study have not been adjusted for flow distortion. Anemometers are usually located above the bridge and may be in an area of either wind acceleration or deceleration caused by distortion of the air flowing over the bridge. The magnitude of the flow distortion has been modelled for research vessels and for tanker and bulk-carrier merchant vessels, by Moat et al. (2005, 2006a,b). The wind speed bias depends on the ship type and dimensions, the details of structure around the anemometer location, instrument mast height and relative wind direction. New fields were added to Pub. 47 in 2002, designed to help in the quantification of flow distortion biases (Kent et al., 2007). However, more research is required to develop corrections for flow distortion based on these metadata, and to determine whether there is a timevarying contribution from this effect.

The study of trends in spatially averaged data over a sub-set of the full global ocean area is complicated by the presence of regions of real inter-annual variability and both positive and negative trends within the analysis area. The trend in the spatial average depends on the particular regional trends that contribute to the overall value. Figure 9 clearly shows regional variations in trend, both positive and negative, in annual mean reanalysis winds from 1982 to 2002, while the spatially averaged reanalysis winds increase only slightly (roughly $1 \%$ decade $^{-1}$ or less, Figure 7 and Table II). Over this relatively short period of two decades, regional variations in trend could just as likely be reflections of inter-annual variability in atmospheric circulation patterns such as the El Nino Southern Oscillation or the North Atlantic Oscillation, as of any longer term trend. Thus, they are sensitive to the time interval considered. Despite the inherent uncertainties, the overwhelmingly positive trends in the ship data suggest that there are residual spurious positive trends in the adjusted ship winds, which are stronger for estimated than for measured winds.

The strong negative trend in height-adjusted measured ship winds for the period 1982-2002 in the northern latitudes of the N. Atlantic $\left(55^{\circ}-65^{\circ} \mathrm{N}\right)$ is somewhat unexpected, given trends in measured ship winds elsewhere, and requires further investigation.

Sources of more homogeneous wind data could be used to validate the VOS winds and wind trends, such as research-vessel observations (Gulev, 1999; Smith et al., 2001), or buoy data. Moored buoy data are available over or near the continental shelves in the N. Pacific and N. Atlantic, beginning in the late 1970 s at a few U.S. sites, and at increasing numbers of locations during the 1980s and 1990s. Moored buoy data are also available over the open tropical oceans, beginning with the Tropical Atmosphere Ocean (TAO) buoy array, developed in the 1980s. Careful quality-control and examination of buoy time series is required, as the expected life-time of the anemometers used is similar to the period between service visits and archives can include data from failing or failed sensors (Thomas et al., 2005). In the future, it may be possible to use global marine wind data sets based on homogenized satellite data. Comparison with surfacepressure-gradient related variables from observations or reanalysis data might help to validate VOS wind trends (e.g. Wang et al., 2006b) although care is needed in choosing methods that use pressure data (Lindau, 2006). In addition, differences between vector and scalar-mean wind speed trends related to trends in wind steadiness should be assessed (Lindau, 2006).

Greater numbers of ICOADS wind reports than was possible for this study could be used. Matching of ship reports to the metadata was hampered earlier in the period by lack of callsign information in many archived ship reports. This in turn reduced the number of measured wind reports that could be used. It may be possible in the future to substitute additional callsigns from GTS reports into the preferred logbook reports (which in earlier years usually contain a numeric identifier), as part of the ICOADS duplicate elimination procedure. Similarly, in archived reports with an ambiguous wind method indicator (WI) and a duplicate GTS report, it may be possible to determine the correct indicator from the GTS report. Ambiguities in WI could also be resolved through examination of wind speed distributions 
in different source archives and for different individual ships. Greater numbers of measured wind reports from ships without height metadata could be adjusted and used by estimating the anemometer height from default values varying in time and space and in ship size and type (Kent et al., 2007).

Further corrections to ship wind observations could improve the ICOADS wind data. Ideally, the effects of atmospheric stability should be accounted for when adjusting wind measurements for height. Daily gridded air and sea temperature fields could be used to estimate the atmospheric stability when observations are missing from ship reports. More research is required to account for flow distortion effects in measured winds using newly available metadata. The utility of developing time, country, source archive, or night-day varying Beaufort equivalent scales should be investigated. To extend the time series to the present day it will be necessary to determine which reports contain height-adjusted measured winds from TurboWin.

\section{Conclusions}

Metadata were used to adjust individual ICOADS wind speeds for known inhomogeneities due to changing observing methods and measurement heights. The impact of the adjustments on wind speed trends was assessed. During the late 1970s, the proportion of reports flagged as measured increased substantially in ICOADS. Average anemometer heights vary spatially and increased over time from $20 \mathrm{~m}$ in the early 1980 s to over $30 \mathrm{~m}$ two decades later.

Measured ship winds prior to adjustment for anemometer height are substantially stronger than estimated winds. The adjustment of measured winds to $10-\mathrm{m}$, and of estimated winds using the revised Beaufort equivalent scale of Lindau (1995a), makes the winds more homogeneous, and removes much of the increasing trend in the period 1958-1981. The remaining increase, of just less than $0.1 \mathrm{~ms}^{-1}$ decade $^{-1}$, is in reasonable agreement with the weak trend in the ERA40 reanalysis winds. Over the regions we were able to analyse (mostly restricted to the $\mathrm{NH}$ ), the adjustments result in good agreement in the annual mean measured and estimated winds in the early 1980s. These results support the conclusion (e.g. Cardone et al., 1990) that a spurious increasing trend in marine winds can be largely explained by an increase in the proportion of measured to estimated wind reports and by increasing anemometer heights, for the period from the late 1950 s to the early 1980 s. The adjustment to measured winds for anemometer height had most impact on trends; the effect of the Lindau (1995a) adjustment on estimated trends in mean wind speed was small.

After 1982, the adjusted winds show increasing inhomogeneity. Annual average estimated winds become greater than measured, and there is an upward (but differing) trend in winds from both methods. From 1982 to 2002, adjusted estimated winds increase
$0.4 \mathrm{~ms}^{-1}$ decade $^{-1}\left(6 \%\right.$ decade $\left.^{-1}\right)$ and height-adjusted measured winds increase about $0.2 \mathrm{~ms}^{-1}$ decade $^{-1}(3 \%$ decade $\left.^{-1}\right)$. Reanalysis winds increase at just under $0.1 \mathrm{~ms}^{-1}$ decade $^{-1}$ (less then $1 \%$ decade $^{-1}$ ). Further analysis would be required to understand whether or how any of the factors, such as airflow distortion, changes in ship types and recruiting countries, or changes in calculation of true wind, might contribute to a timevarying residual bias in height-adjusted measured winds.

Some of the factors that influence bias in measured wind speeds could contribute to a time-varying trend in winds reported as estimated. Kent et al. (1993) showed that reports from ships' estimated winds were biased low at night, but the tendency for a low bias was reduced for those ships carrying an anemometer. We found very little day - nighttime bias in measured ship winds. We also found a reduction in day - nighttime bias in estimated wind speeds during the 1980s and 1990 s, indicating the increasing influence of onboard anemometers (uncorrected for height) on winds reported as estimated. We also conclude that average diurnal wind speed variations are small over the open-ocean, and that an earlier study (Dai and Deser, 1999) overestimated the magnitude of these variations.

The annual mean spatially averaged adjusted ship winds were consistently stronger than reanalysis nearsurface mean wind speeds for the same analysis area, throughout the period. This supports the conclusions of other studies that reanalysis winds are biased low. However, averaged over the full analysis area, reanalysis winds appear to be homogenous in the period 1982-2002. While there appear to be real trends (both positive and negative) on a regional scale during this period, in ship winds these appear to be overlaid by an apparently spurious positive trend (larger for estimated than for measured winds). This underscores the need to validate long-term trends using known homogeneous sources (Swail et al., 1999).

Although this study has shown that problems remain with the ICOADS wind record, we note that the prospects for resolution of the outstanding issues are good. Improved metadata availability, statistical techniques and computing power mean that we have the capability to better understand and correct biases in this essential climate record. ICOADS ship winds are an important tool for understanding and validating both model and remotely sensed wind speed estimates, but require careful analysis if we are to realize their full potential.

\section{Acknowledgements}

This work was partially funded by the Canadian Federal Program of Energy Research and Development, Environment Canada and by the Natural Environment Research Council Core Strategic Research Programme Large-Scale Long-Term Ocean Circulation. ICOADS individual observations were obtained from NCAR (http://dss.ucar.edu/pub/coads/). ICOADS monthly summaries and the NCEP-NCAR Reanalysis output were 
provided by the NOAA Earth System Research Laboratory, Boulder, Colorado, USA, via their Web site at http://www.cdc.noaa.gov/. VOS metadata were provided by the WMO. ECMWF ERA-40 data were obtained from the ECMWF data server. Figures were generated using the Ferret analysis tool from the NOAA Pacific Marine Environmental Laboratory (http://ferret.pmel.noaa.gov/ Ferret/). We appreciate the many useful suggestions for improvements to the paper, provided by Scott Woodruff and two anonymous referees.

\section{References}

Berry DI, Kent EC, Taylor PK. 2004. An analytical model of heating errors in marine air temperatures from ships. Journal of Atmospheric and Oceanic Technology 21: 1198-1215, DOI: 10.1002/joc.1178.

Bourassa MA, Romero R, Smith SR, O'Brien JJ. 2005. A new FSU winds climatology. Journal of Climate 18: 3686-3696, DOI: 10.1175/JCLI3487.1.

Bunker AF. 1980. Trends of variables and energy fluxes over the Atlantic Ocean from 1948 to 1972. Monthly Weather Review 108: 720-732, DOI: 10.1175/1520-0493(1980)108 <0720:TOVAEF> 2.0.CO;2.

Caires S, Sterl A. 2003. Validation of ocean wind and wave data using triple collocation. Journal of Geophysical Research 108: 3098, DOI: 10.1029/2002JC001491.

Cardone VJ. 1969. Specification of the wind distribution in the marine boundary layer for wave forecasting. Report No TR691. Department of Meteorology and Oceanography Geophysical Sciences, Laboratory, New York University School of Engineering and Science: New York; 131 [NTIS AD 702 490].

Cardone VJ, Greenwood JG, Cane MA. 1990. On trends in historical marine data. Journal of Climate 3: 113-127.

da Silva AM, Young CC, Levitus S. 1995. Toward a revised Beaufort Equivalent Scale. In Proceedings of the International COADS Winds Workshop, Diaz HF, Isemer H-J (eds). Berichte aus dem Institut für Meereskunde and der Christian-Albrechts-Univerität Report No. 265: Kiel, 1 May - 2 June 1994; 270-286 [http://icoads.noaa.gov/kiel].

Dai A, Deser C. 1999. Diurnal and semidiurnal variations in global surface wind and divergence fields. Journal of Geophysical Research 104: 31109-31125, DOI: 10.1029/1999JD900927.

Diaz HF, Quan X, Fu C. 1995. Marine surface wind changes during 1978-1992: an estimation based on COADS. In Proceedings of the International COADS Winds Workshop, Diaz HF, Isemer H-J (eds). Berichte aus dem Institut für Meereskunde and der ChristianAlbrechts-Univerität Report No. 265: Kiel, 1 May - 2 June 1994; 48-53 [http://icoads.noaa.gov/kiel/]

Dobson FW. 1981. Review of reference height for and averaging time of surface wind measurements at sea. Marine Meteorology and Related Oceanographic Activities Report No. 3. World Meteorological Organization, Geneva; 64.

Goswami BN, Sengupta D. 2003. A note on the deficiency of NCEP/NCAR reanalysis surface winds over the equatorial Indian Ocean. Journal of Geophysical Research 108(C4): 3124, DOI: 10.1029/2002JC001497.

Graham NE, Diaz HF. 2001. Evidence for intensification of North Pacific winter cyclones since 1948. Bulletin of the American Meteorological Society 82: 1869-1983, DOI: 10.1175/15200477(2001)082<1869:EFIONP>2.3.CO;2.

Gulev SK. 1999. Comparison of COADS Release 1a winds with instrumental measurements in the Northwest Atlantic. Journal of Atmospheric and Oceanic Technology 16: 133-145, DOI: 10.1175/1520-0426(1999)016<0133:COCRWW>2.0.CO;2.

Hines KM, Bromwich DH, Marshall GJ. 2000. Artificial surface pressure trends in the NCEP-NCAR reanalysis over the Southern Ocean and Antarctica. Journal of Climate 13: 3940-3952, DOI: 10.1175/1520-0442(2000)013<3940:ASPTIT>2.0.CO;2.

Isemer H-J. 1992. Comparison of estimated and measured marine surface wind speed. In Proceedings of the International COADS Workshop, Diaz HF, Wolter K, Woodruff SD. (eds). NOAA Environmental Research Laboratories, Climate Research Division, Boulder, Colorado, 13-15 January 1992; 142-158.

Isemer H-J. 1995. Trends in marine surface winds speed: ocean weather stations versus voluntary observing ships. In Proceedings of the
International COADS Winds Workshop, Diaz HF, Isemer H-J (eds) Berichte aus dem Institut für Meereskunde and der ChristianAlbrechts-Univerität Report No. 265: Kiel, 1 May - 2 June 1994; 68-84 [http://icoads.noaa.gov/kiel].

Isemer H-J, Hasse L. 1991. The scientific Beaufort equivalent scale: effects on wind statistics and climatological air-sea flux estimates in the North Atlantic Ocean. Journal of Climate 4: 819-836, DOI: 10.1175/1520-0442(1991)004<0819:TSBESE > 2.0.CO;2.

Jiang C, Cronin MF, Kelly KA, Thompson L. 2005. Evaluation of a hybrid satellite- and NWP-based turbulent heat flux product using Tropical Atmosphere-Ocean (TAO) buoys. Journal of Geophysical Research 110(C9): C09007, DOI: 10,1029/2004JC002824.

Kalnay E, Kanamitsu M, Kistler R, Collins W, Deaven D, Gandin L, Iredell M, Saha S, White G, Woollen J, Zhu Y, Chelliah M, Ebisuzaki W, Higgins W, Janowiak J, Mo KC, Ropelewski C, Wang J, Leetmaa A, Reynolds R, Jenne R, Joseph D. 1996. The NCEP/NCAR 40-year reanalysis project. Bulletin of the American Meteorological Society 77: 437-471, DOI: 10.1175/15200477(1996)077<0437:TNYRP $>2.0$. CO;2.

Kaufeld L. 1981. The development of a new Beaufort equivalent scale. Meteorologische Rundschau 34: 17-23.

Kent EC, Taylor PK. 1997. Choice of a Beaufort equivalent scale. Journal of Atmospheric and Oceanic Technology 14: 228-242, DOI: 10.1175/1520-0426(1997)014<0228:COABES > 2.0.CO;2.

Kent EC, Taylor PK, Challenor PG. 1998. A comparison of ship and scatterometer-derived wind speed data in open ocean and coastal areas. International Journal of Remote Sensing 19: 3361-3381, DOI: 10.1080/014311698214046.

Kent EC, Taylor PK, Truscott BS, Hopkins JA. 1993. The accuracy of Voluntary Observing Ship's Meteorological Observations. Journal of Atmospheric and Oceanic Technology 10: 591-608, DOI: 10.1175/1520-0426(1993)010<0591:TAOVOS $>2.0$. CO $; 2$

Kent EC, Woodruff SD, Berry DI. 2007. WMO Publication No. 47 metadata and an assessment of observation heights in ICOADS. Journal of Atmospheric and Oceanic Technology 24: 214-234.

Kistler R, Kalnay E, Collins W, Saha S, White G, Woollen J, Chelliah M, Ebisuzaki W, Kanamitsu M, Kousky V, van den Dool H, Jenne R, Fiorino M. 2001. The NCEP-NCAR 50-year reanalysis: monthly means CD-ROM and documentation. Bulletin of the American Meteorological Society 82: 247-267, DOI: 10.1175/1520-0477(2001)082<0247:TNNYRM>2.3.CO;2.

Kubota M, Iwasaka N, Kizu S, Konda M, Kutsuwada K. 2002. Japanese ocean flux data sets with use of remote sensing observations (J-OFURO). Journal of Oceanography 58: 213-225, DOI: $10.1023 / \mathrm{A}: 1015845321836$.

Lindau R. 1995a. A new Beaufort equivalent scale. In Proceedings of the International COADS Winds Workshop, Diaz HF, Isemer H-J (eds). Berichte aus dem Institut für Meereskunde and der ChristianAlbrechts-Univerität Report No. 265: Kiel, 1 May - 2 June 1994; 232-252 [http://icoads.noaa.gov/kiel/]

Lindau R. 1995b. Time dependent calibration of marine Beaufort estimates using individual pressure differences. In Proceedings of the International COADS Winds Workshop, Diaz HF, Isemer H-J (eds). Berichte aus dem Institut für Meereskunde and der ChristianAlbrechts-Univerität Report No. 265: Kiel, 1 May - 2 June 1994; 253-269 [http://icoads.noaa.gov/kiel/].

Lindau R. 2003. Errors of Atlantic air-sea fluxes derived from ship observations. Journal of Climate 16: 783-788, DOI: 10.1175/15200442(2003)016<0783:EOAASF > 2.0.CO;2.

Lindau R. 2006. The elimination of spurious trends in marine wind data using pressure observations. International Journal of Climatology 26: 797-817, DOI: 10.1002/joc.1284.

McCabe GJ, Clark MP, Serreze MC. 2001. Trends in northern hemisphere surface cyclone frequency and intensity. Journal of Climate 14: 2763-2768, DOI: 10.1175/1520-0442(2001)014<2763. TINHSC $>2.0 . \mathrm{CO} ; 2$

Mears CA, Smith DK, Wentz FJ. 2001. Comparison of Special Sensor Microwave Imager and buoy-measured wind speeds from 1987 to 1997. Journal of Geophysical Research 106: 11719-11729, DOI: 10.1029/1999JC000097.

Moat BI, Yelland MJ, Pascal RW, Molland AF. 2005. An overview of the airflow distortion at anemometer sites on ships. International Journal of Climatology 25: 997-1006, DOI: 10.1002/joc.1177.

Moat BI, Yelland MJ, Pascal RW, Molland AF. 2006a. Quantifying the airflow distortion over merchant ships, Part I: validation of a CFD model. Journal of Atmospheric and Oceanic Technology 23 341-350, DOI: $10.1175 / \mathrm{JTECH} 1858.1$.

Moat BI, Yelland MJ, Pascal RW, Molland AF. 2006b. Quantifying the airflow distortion over merchant ships, Part II: application of 
model results. Journal of Atmospheric and Oceanic Technology 23 351-360, DOI: 10.1175/JTECH1859.1.

National Climatic Data Center (NCDC). 1968. TDF-11 Reference Manual. National Climatic Data Center: Asheville, NC; 138.

Paciorek CJ, Risbey JS, Ventura V, Rosen RD. 2002. Multiple indices of Northern Hemisphere Cyclone Activity, Winters 1949-1999. Journal of Climate 15: 1573-1590, DOI: 10.1175/15200442(2002)015<1573:MIONHC > 2.0.CO;2.

Peterson EW, Hasse L. 1987. Did the Beaufort scale or the wind climate change? Journal of Physical Oceanography 17: 1071-1074, DOI: 10.1175/1520-0485(1987)017<1071:DTBSOT>2.0.CO;2.

Posmentier ES, Cane MA, Zebiak S. 1989. Tropical Pacific climate trends since 1960. Journal of Climate 2: 731-736, DOI 10.1175/1520-0442(1989)002<0731:TPCTS $>2.0$. CO 2 .

Ramage CR. 1987. Secular changes in reported surface wind speeds over the ocean. Journal of Applied Meteorology 26: 525-528, DOI: 10.1175/1520-0450(1987)026<0525:SCIRSW > 2.0.CO;2.

Serreze MC, Carse F, Barry RG, Rogers JC. 1997. Icelandic low cyclone activity: climatological features, linkages with the NAO, and relationships with recent changes in the northern hemisphere circulation. Journal of Climate 10: 453-464, DOI: 10.1175/15200442(1997) $010<0453:$ ILCACF $>2.0 . C O ; 2$.

Slutz RJ, Lubker SJ, Hiscox JD, Woodruff SD, Jenne RL, Joseph DH, Steurer PM, Elms JD. 1985. Comprehensive Ocean-atmosphere Data Set; Release 1. NOAA Environmental Research Laboratories, Climate Research Program: Boulder, CO; 268, (NTIS PB86-105723).

Smith SD. 1988. Coefficients for sea surface wind stress, heat flux, and wind profiles as a function of wind speed and temperature. Journal of Geophysical Research 93: 15467-15472, DOI: 10.1029/88JC03508.

Smith SR, Legler DM, Verzone KV. 2001. Quantifying uncertainties in NCEP reanalyses using high-quality research vessel observations. Journal of Climate 14: 4062-4072, DOI: 10.1175/15200442(2001)014<4062:QUINRU>2.0.CO;2.

Sterl A. 2004. On the (in-)homogeneity of reanalysis products. Journal of Climate 17: 3866-3873, DOI: 10.1175/15200442(2004)017<3866:OTIORP > 2.0.CO;2

Swail VR, Cox AT. 2000. On the use of NCEP-NCAR reanalysis surface marine wind fields for a long-term North Atlantic wave hindcast Journal of Atmospheric and Oceanic Technology 17(4): 532-545, DOI: $10.1175 / 1520-0426(2000) 017<0532$ :OTUONN $>2.0 . C O ; 2$.

Swail VR, Cox A, Cardone V. 1999. Trends and potential biases in NCEP-driven ocean wave hindcasts. In Proceedings of the Second WCRP (World Climate Research Program) International Conference on Reanalyses, WCRP-109, WMO/TD-No. 985, World Meteorological Organization, Geneva, 23-27 August 1999, Reading, UK; 129-132.

Thomas BR, Kent EC, Swail VR. 2005. Methods to homogenize wind speeds from ships and buoys. International Journal of Climatology 25: 979-995, DOI: 10.1002/joc.1176.

Thompson DWJ, Wallace JM. 2000. Annular modes in the extratropical circulation part I. Month-to-Month variability. Journal of Climate 15: 1000-1016, DOI: 10.1175/1520-0442(2000)013<1000: AMITEC $>2.0 . \mathrm{CO} ; 2$.

Uppala SM, Kållberg PW, Simmons AJ, Andrae U, da Costa Bechtold V, Fiorino M, Gibson JK, Haseler J, Hernandez A, Kelly GA, Li X, Onogi K, Saarinen S, Sokka N, Allan RP, Andersson E, Arpe K, Balmaseda MA, Beljaars ACM, van de Berg L, Bidlot J, Bormann N, Caires S, Chevallier F, Dethof A, Dragosavac M, Fisher M, Fuentes M, Hagemann S, Hólm E, Hoskins BJ, Isaksen L, Janssen PAEM, Jenne R, McNally AP, Mahfouf J-F, Morcrette J-J, Rayner NA, Saunders RW, Simon P,
Sterl A, Trenberth KE, Untch A, Vasiljevic D, Viterbo P, Woollen J. 2005. The ERA-40 re-analysis. Quarterly Journal of the Royal Meteorological Society 131: 2961-3012, DOI: 10.1256/qj.04.176.

Walmsley JL. 1988. On theoretical wind speed and temperature profiles over the sea with applications to data from Sable Island, N.S. Atmosphere-Ocean 26: 202-233.

Wang XL, Wan H, Swail VR. 2006a. Observed changes in cyclone activity in Canada and their relationships to major circulation regimes. Journal of Climate 19(6): 896-915, DOI: 10.1175/JCLI3664.1.

Wang XL, Swail VR, Zhang X, Zwiers FW, Allen M. 2006b. Detection of human influence on trends of North Atlantic ocean wave heights and atmospheric storminess. In 9th International Workshop on Wave Hindcasting and Forecasting, Environment Canada, Toronto: Victoria, BC, Canada, 24-29 Sept. 2006, [http://www.waveworkshop.org/9thWaves/index.htm].

Ward MN, Hoskins BJ. 1996. near-surface wind over the global ocean 1949-1988. Journal of Climate 9: 1877-1895, DOI: 10.1175/15200442(1996) $009<1877$ :NSWOTG $>2.0$. CO; 2 .

The WASA (Waves and Storms in the North Atlantic) Group. 1998. Changing waves and storms in the NE Atlantic? Bulletin of the American Meteorological Society 79(5): 741-760, DOI: 10.1175/1520-0477(1998)079<0741:CWASIT > 2.0.CO;2.

Whysall KDB, Cooper NS, Bigg GR. 1987. Long-term changes in the tropical Pacific surface wind field. Nature 327: 216-219, DOI: $10.1038 / 327216 \mathrm{a} 0$.

WMO. 1970. The Beaufort scale of wind force. Reports on Marine Science Affairs, No. 3. World Meteorological Organization: Geneva; 22

Woodruff SD, Slutz RJ, Jenne RL, Steurer PM. 1987. A comprehensive ocean atmosphere dataset. Bulletin of the American Meteorological Society 68: 1239-1250, DOI: 10.1175/15200477(1987)068<1239:ACOADS > 2.0.CO; 2.

Woodruff SD, Diaz HF, Elms JD, Worley SJ. 1998. COADS Release 2 data and metadata enhancements for improvements of marine surface flux fields. Physics and Chemistry of the Earth 23: 517-527, DOI: 10.1016/S0079-1946(98)00064-0.

Woodruff SD, Worley SJ, Arnott JA, Diaz HF, Elms JD, Jackson M, Lubker SJ, Parker DE. 2003. COADS updates and the blend with the UK Met Office Marine Data Bank. Advances in the Applications of Marine Climatology - The Dynamic Part of the WMO Guide to the Applications of Marine Meteorology, WMO/TD-No. 1081 (JCOMM Technical Report No. 13), World Meteorological Organization, Geneva: 3-10 (CD-ROM).

Worley SJ, Woodruff SD, Reynolds RW, Lubker SJ, Lott N. 2005. ICOADS Release 2.1 data and products. International Journal of Climatology 25: 823-842, DOI: 10.1002/joc. 1166.

Wright PB. 1988. On the reality of climatic changes in wind over the Pacific. Journal of Climatology 8: 521-527.

Wu R, Xie S-P. 2003. On equatorial Pacific surface wind changes around 1977: NCEP-NCAR reanalysis versus COADS observations. Journal of Climate 16: 167-173, DOI: 10.1175/15200442(2003)016<0167:OEPSWC > 2.0.CO;2.

Yelland MJ, Moat BI, Pascal RW, Berry DI. 2002. CFD model estimates of the airflow over research ships and the impact on momentum flux measurements. Journal of Atmospheric and Oceanic Technology 19: 1477-1499, DOI: 10.1175/15200426(2002)019<1477:CMEOTA > 2.0.CO;2.

Yuan XJ. 2004. High wind evaluation in the Southern Ocean. Journal of Geophysical Research 109(D13101): DOI: 10.1029/2003JD004179. 